\title{
On the role of liquidity in emerging markets stock prices ${ }^{\text {is }}$
}

\author{
Michael Donadelli*, Lorenzo Prosperi ${ }^{1}$ \\ Department of Economics and Finance, LUISS Guido Carli University, Viale Romania 32, 00197 Rome, Italy
}

\section{A R T I C L E I N F O}

\section{Article history:}

Received 30 December 2011

Accepted 7 June 2012

Available online 4 July 2012

\section{Keywords:}

Excess returns

Emerging stock markets

Global risk factors

Liquidity

\begin{abstract}
A B S T R A C T
This paper investigates the impact of liquidity on emerging markets' stock prices. Particular attention is given to the estimation of Jensen's alpha and the quantity of risk. Our empirical analysis gives rise to two main issues. The first is related to the presence of an extra premium, i.e. "alpha puzzle". The second is the time-varying component of the quantity of risk, i.e. "beta puzzle". We find that local liquidity factors do not explain the presence of positive and statistically significant alphas. This puzzle is solved by means of transaction costs. In addition, we show that global liquidity factors, such as VIX and Open Interest, statistically affect the market price of risk. Our empirical finding proves the time varying nature of the global risk factors. Finally, we argue that standard asset pricing models cannot solve the two puzzles simultaneously.
\end{abstract}

(c) 2012 University of Venice. Published by Elsevier Ltd. All rights reserved.

\section{Introduction}

It is largely accepted that differences in risk and return between developed and emerging stock markets are frequently huge. Emerging markets are characterized by volatile, but generous returns. The equity risk premium (ERP) provides an intuitive measure of the extent by which agents in an economy need to be compensated for the riskiness of the productive assets of that economy. ${ }^{2}$ We claim that investing in emerging markets, which usually involves countries with less stable governments and economies, is still perceived to be extremely risky. Not surprisingly, emerging markets offer higher average excess returns than developed markets. To find the main causes of such asset pricing gap, we adopt an increasingly popular approach. It considers local and global movements in liquidity as determinant in stock prices.

Based on different liquidity measures, several studies have explored the effect of liquidity on asset pricing. Fujimoto (2003) argues that over the past two decades research on liquidity has been fundamental to measure its impact on asset prices. Amihud and Mendelson (1986), and Eleswarapu (1997) find a significant positive relationship between the bid-ask spreads and the stock returns. Eleswarapu and Reinganum (1993) find that the liquidity effect is restricted to the month of January. Based on Kyle's (1985) model, Brennan and Subrahmanyam (1996) estimate the price impact of a trade, and find that it is significantly positively related to average returns. ${ }^{3}$

The illiquidity-return relationship has also been studied extensively using different liquidity measures. For example, Chalmers and Kadlec (1998) use an amortized bid-ask spread. Brennan et al. (1998) use a daily dollar trading volume

\footnotetext{
We are indebted to Nicola Borri for his invaluable comments and suggestions at all stages of this project. We thank Andrea Collevecchio, Giorgio Di Giorgio, Daniele Massacci, Salvatore Nisticò, Roberto Pancrazi, Giuseppe Ragusa, Pietro Reichlin, Valerio Scalone, Federico Silvestri, Giovanna Vallanti, Paolo Vitale, and seminar audiences at various seminars and conferences for their comments which substantially improved the paper. All errors are our own.

* Corresponding author. Tel.: +3906 85225972.

E-mail addresses: mdonadelli@luiss.it (M. Donadelli), lorenzo.prosperi@gmail.com (L. Prosperi).

1 Tel.: + 390685225587.

${ }^{2}$ Throughout the paper we use the terms equity risk premium, excess return, or stock price interchangeably.

${ }^{3}$ Easley et al. (2002) obtain a similar result.
} 
measure. Datar et al. (1998) provide an alternative test of Amihud and Mendelson's (1986) model using the turnover rate (i.e. number of shares traded as a fraction of the number of shares outstanding) as a proxy for liquidity. Their empirical results suggest that liquidity plays a significant role in explaining the cross-sectional variation in stock returns.

In addition to the level of liquidity, other aspects of liquidity are also found to influence expected returns, such as volatility and persistency of liquidity measures. Chordia et al. (2001b) find that the variability of dollar volume and share turnover has a significant negative effect on stock returns. Chan (2002) documents that stocks with greater persistence in illiquidity have higher average returns. Akbas et al. (2011) suggest that the positive correlation between the volatility of liquidity and expected returns is caused by investors' risk aversion. They claim that higher variation in liquidity implies that a stock may become illiquid with higher probability at a time when it is traded. If a stock's liquidity fluctuates within a wider range around its mean compared to similar stocks, an investor holding the stock may be exposed to a higher probability of low liquidity at the time he needs to sell the stock. Using monthly series of the turnover, dollar volume and volatility of liquidity, Chordia et al. (2001b) show a strong negative relation between the volatility of liquidity and expected returns. They argue that their finding is puzzling since risk averse investors should require a risk premium for holding stocks whose liquidity is volatile. Amihud et al. (2005) emphasizes the importance of volatility of liquidity and argue that risk averse investors should require compensation for bearing the risk associated with the time-variation of liquidity.

The financial literature also provides several empirical studies that aim to capture the impact of liquidity on stock prices. ${ }^{4}$ Acharya and Pedersen (2005) propose that the persistence of liquidity forecasts market returns. Intuitively, if liquidity is persistent, higher illiquidity today predicts higher illiquidity next period and results in a higher required rate of return. The liquidity persistence also implies a negative contemporaneous return-illiquidity relationship. The authors claim that if there is a positive illiquidity shock today, investors will anticipate higher illiquidity in the following period and depress current prices in order to earn higher expected returns.

Amihud (2002) uses monthly and annual illiquidity-ratios and finds that expected market illiquidity positively affects ex-ante stock excess return over the period 1964-1997. Jones (2002) uses the proportional spread of Dow Jones stocks and the share turnover of NYSE stocks over the last century and finds that both spread and turnover predict annual excess market returns up to three years ahead. Baker and Stein (2002) obtain a similar result using annual aggregate NYSE turnover over the period 1932-1998.

The negative contemporaneous relation between the market's return and illiquidity is documented by Amihud (2002), Chordia et al. (2001b), and Pastor and Stambaugh (2003). Amihud and Mendelson (1990) suggest that the stock market crash of 1987 can be interpreted as a realization of expected illiquidity, which led to a change in investors' perception about future liquidity and contributed to the decline in stock prices. The positive correlation between volatility of liquidity measures and expected returns, as well as the negative correlation between liquidity and expected stock returns, suggest that risk averse investors require a premium for holding stocks with high variation in liquidity.

In this project, we first examine differences between developed and emerging markets' excess returns. Our empirical results show that such differences still take place. In contrast to a vast empirical literature on asset pricing, which mainly adopts data from the United States, ${ }^{5}$ our analysis is based on a heterogeneous basket of countries. Following Bekaert et al. (2007), we try to observe the impact of liquidity on a number of markets where it ought to be particularly important.

Adopting standard linear asset pricing techniques we focus on the estimation of Jensen's alpha and the quantity of risk. Our empirical analysis gives rise to two main issues. The first is related to the presence of an extra premium, i.e. "alpha puzzle". The second is the time-varying component of the quantity of risk, i.e. "beta puzzle". Our findings contribute to the literature in the following ways.

Section 2, examines the performances of 13 developed and 19 emerging country stock indices, and 6 macro-equallyweighted portfolios. This procedure provides an up to date empirical view of the differences between developed and emerging average excess returns. In Sections 3 and 4, the "alpha puzzle" and its implications for model's validity are discussed. We generally find that local liquidity factors are not able to explain the presence of positive and statistically significant alphas. Section 5 presents a simple theoretical partial equilibrium model aimed at solving the puzzle. We prove that the puzzle can be solved by means of transaction costs. Section 6 shows that global liquidity factors, such as VIX and Open Interest, statistically affect the market price of risk. In addition, we argue that these puzzles cannot be solved simultaneously via standard asset pricing models. Section 7 concludes.

\section{Data description and preliminary analysis}

We use the Morgan Stanley Capital International (MSCI) Total Return Index for developed and emerging equity markets. All returns are monthly total returns denominated in US dollars. ${ }^{6}$ We evaluate US\$ returns in developed and

\footnotetext{
${ }^{4}$ See Acharya and Pedersen (2005), Amihud (2002); Baker and Stein (2002), and Jones (2002), among others.

5 Amihud and Mendenlson (1986), Brennan and Subrahmanyam (1996), Datar et al. (1998), Chordia, Roll and Subrahmanyam (2000) try to quantify the role of liquidity in US expected stock returns. Pastor and Stambaugh (2003) find that US expected stock returns are related cross-sectionally to the sensitivities of returns to fluctuations in aggregate liquidity.

${ }^{6}$ The MSCI Total Return Index measure the price performance of markets with the income from constituent dividend payments. The MSCI Daily Total Return (DTR) Methodology reinvests an index constituents dividends at the close of trading on the day the security is quoted ex-dividend (the ex-date).
} 
Table 2.1

List of MSCI total return indices.

\begin{tabular}{|c|c|c|c|c|}
\hline \multirow{2}{*}{$\begin{array}{l}\text { Developed economies } \\
\text { G7 and Others }\end{array}$} & \multicolumn{4}{|c|}{ Emerging markets } \\
\hline & Asia & Latina America & Africa & Eastern Europe \\
\hline Australia & China & Argentina & Egypt & Czech Rep. \\
\hline Canada & India & Brazil & Morocco & Hungary \\
\hline France & Indonesia & Chile & South Africa & Poland \\
\hline Germany & Malaysia & Colombia & & Russia \\
\hline Italy & Philippines & Mexico & & Turkey \\
\hline Japan & Korea & & & \\
\hline \multicolumn{5}{|l|}{ Netherlands } \\
\hline \multicolumn{5}{|l|}{ Norway } \\
\hline \multicolumn{5}{|l|}{ Singapore } \\
\hline \multicolumn{5}{|l|}{ Spain } \\
\hline \multicolumn{5}{|l|}{ Switzerland } \\
\hline \multicolumn{5}{|l|}{ United Kingdom } \\
\hline United States & & & & \\
\hline
\end{tabular}

Table 2.2

Developed stock markets-ERP descriptive statistics (full sample).

\begin{tabular}{|c|c|c|c|c|c|c|c|}
\hline Country (MSCI) & Sample & Obs. & Mean (\%) & St. Dev. (\%) & Skewness & Kurtosis & J. Bera \\
\hline Australia & $01 / 70-12 / 10$ & 492 & 0.60 & 7.10 & -0.69 & 7.41 & $437.76(0.00)$ \\
\hline Canada & $01 / 70-12 / 10$ & 492 & 0.57 & 5.81 & -0.52 & 5.26 & $126.55(0.00)$ \\
\hline France & $01 / 70-12 / 10$ & 492 & 0.60 & 6.62 & -0.13 & 4.34 & $38.23(0.00)$ \\
\hline Germany & $01 / 70-12 / 10$ & 492 & 0.57 & 6.38 & -0.29 & 4.34 & $43.33(0.00)$ \\
\hline Italy & $01 / 70-12 / 10$ & 492 & 0.30 & 7.42 & 0.16 & 3.80 & $15.35(0.00)$ \\
\hline Japan & $01 / 70-12 / 10$ & 492 & 0.53 & 6.30 & 0.21 & 3.62 & $11.57(0.00)$ \\
\hline Netherlands & $01 / 70-12 / 10$ & 492 & 0.70 & 5.64 & -0.49 & 5.20 & $118.67(0.00)$ \\
\hline Norway & $01 / 70-12 / 10$ & 492 & 0.82 & 8.02 & -0.38 & 4.48 & $56.57(0.00)$ \\
\hline Singapore & $01 / 70-12 / 10$ & 492 & 0.86 & 8.44 & 0.37 & 8.48 & $627.25(0.00)$ \\
\hline Spain & $01 / 70-12 / 10$ & 492 & 0.55 & 6.76 & -0.16 & 4.68 & $60.24(0.00)$ \\
\hline Switzerland & $01 / 70-12 / 10$ & 492 & 0.63 & 5.37 & -0.14 & 4.21 & $31.68(0.00)$ \\
\hline United Kingdom & $01 / 70-12 / 10$ & 492 & 0.59 & 6.50 & 1.17 & 13.98 & $2580.83(0.00)$ \\
\hline United States & $01 / 70-12 / 10$ & 492 & 0.42 & 4.54 & -0.41 & 4.71 & $73.27(0.00)$ \\
\hline
\end{tabular}

emerging markets versus US\$ risk-free rates of return. Data on risk-free rate of return are from the Fama-French data library. We rely on the one-month Treasury Bill rate.

Our analysis is focused on 13 developed markets, 19 emerging markets and 6 macro-area equally weighted portfolios. The list of countries is illustrated in Table 2.1.

For developed markets, we restrict our analysis to the largest world's economies. Equity markets' data for developed economies run from Dec 69 to Dec 10. Emerging markets' data run from Dec 87 (or later) to Dec 10. ${ }^{7}$ Countries' excess returns are constructed by subtracting the risk-free rate to the stock returns (see Eq. (2.1)).

$$
\frac{M S C I T R I_{i, t+1}-M S C I T R I_{i, t}}{M S C I T R I_{i, t}}-R_{f, t}=E R P_{i, t+1}
$$

We compute country-by-country descriptive statistics of the excess returns for three different samples: (i) full sample (i.e. based on the maximum number of observations available); (ii) common sample (i.e. Jan 95-Dec 10); (iii) common sample (i.e. Jan 00-Dec 10). The analysis over different samples allows us to partially capture the time varying-component of the ERP. Monthly descriptive statistics are presented in Tables 2.2-2.9.

The preliminary analysis is mainly devoted to study differences between emerging and developed excess returns. Are emerging stock markets still more risky? Do they compensate investors for bearing risk? Are emerging markets still segmented? Does segmentation generate illiquidity?

It is largely accepted that emerging stock markets are characterized by high return and high volatility. We find that the average excess returns in emerging markets are significantly higher than in developed markets. Barry et al. (1997) and Claessens et al. (1995) argue that investing in emerging stock markets is beneficial in a mean-variance framework. They claim that investors are compensated for bearing the extra risk by receiving a higher average return and a low correlation with other markets. On one hand, we confirm the existence of higher returns. On the other hand, the presence of low

\footnotetext{
${ }^{7}$ MSCI TRI data availability: from Dec 87 to Dec 10 (Argentina, Brazil, Chile, Indonesia, Malaysia, Mexico, Philippines, Korea and Turkey); from Dec 92 to Dec 10 (China, Colombia, India, Poland and South Africa ); from Dec 94 to Dec 10 (Czech Republic, Egypt, Hungary, Morocco and Russian).
} 
Table 2.3

Emerging stock markets-ERP descriptive statistics (full sample).

\begin{tabular}{|c|c|c|c|c|c|c|c|}
\hline Country (MSCI) & Sample & Obs. & Mean (\%) & St. Dev. (\%) & Skewness & Kurtosis & J. Bera \\
\hline Argentina & $01 / 88-12 / 10$ & 276 & 2.28 & 15.82 & 1.74 & 11.96 & $1061.99(0.00)$ \\
\hline Brazil & $01 / 88-12 / 10$ & 276 & 2.50 & 15.19 & 0.33 & 7.31 & $218.72(0.00)$ \\
\hline Chile & $01 / 88-12 / 10$ & 276 & 1.50 & 7.08 & -0.24 & 4.63 & $33.11(0.00)$ \\
\hline China & $01 / 93-12 / 10$ & 216 & 0.28 & 10.74 & 0.54 & 5.19 & $53.88(0.00)$ \\
\hline Colombia & $01 / 93-12 / 10$ & 216 & 1.61 & 9.49 & -0.09 & 3.54 & $2.96(0.23)$ \\
\hline Czech Rep. & $01 / 95-12 / 10$ & 192 & 1.22 & 8.62 & -0.29 & 4.25 & $15.13(0.00)$ \\
\hline Egypt & $01 / 95-12 / 10$ & 192 & 1.68 & 9.65 & 0.52 & 5.13 & $44.99(0.00)$ \\
\hline Hungary & $01 / 95-12 / 10$ & 192 & 1.50 & 11.12 & -0.27 & 5.69 & $60.23(0.00)$ \\
\hline India & $01 / 93-12 / 10$ & 216 & 1.06 & 9.03 & 0.06 & 3.68 & $4.24(0.12)$ \\
\hline Indonesia & $01 / 88-12 / 10$ & 276 & 1.68 & 14.81 & 1.64 & 12.54 & $1168.95(0.00)$ \\
\hline Malaysia & $01 / 88-12 / 10$ & 276 & 0.78 & 8.52 & 0.51 & 8.58 & $369.56(0.00)$ \\
\hline Mexico & $01 / 88-12 / 10$ & 276 & 1.80 & 9.24 & -0.50 & 4.59 & $40.76(0.00)$ \\
\hline Morocco & $01 / 95-12 / 10$ & 192 & 0.95 & 5.66 & 0.21 & 4.39 & $16.91(0.00)$ \\
\hline Philippines & $01 / 88-12 / 10$ & 276 & 0.72 & 9.33 & 0.34 & 5.19 & $60.49(0.00)$ \\
\hline Poland & $01 / 93-12 / 10$ & 216 & 1.90 & 14.55 & 2.30 & 20.30 & $2885.96(0.00)$ \\
\hline Russia & $01 / 95-12 / 10$ & 192 & 2.41 & 16.56 & 0.19 & 4.90 & $29.87(0.00)$ \\
\hline South Africa & $01 / 93-12 / 10$ & 216 & 1.15 & 8.11 & -0.52 & 4.16 & $21.82(0.00)$ \\
\hline South Korea & $01 / 88-12 / 10$ & 276 & 0.92 & 11.23 & 1.00 & 8.28 & $366.72(0.00)$ \\
\hline Turkey & $01 / 88-12 / 10$ & 276 & 2.03 & 16.96 & 0.67 & 4.78 & $56.91(0.00)$ \\
\hline
\end{tabular}

Table 2.4

Developed stock markets-ERP descriptive statistics (common sample: Jan 95-Dec 10).

\begin{tabular}{|c|c|c|c|c|c|c|c|}
\hline Country (MSCI) & Sample & Obs. & Mean (\%) & St. Dev. (\%) & Skewness & Kurtosis & J. Bera \\
\hline Australia & $01 / 95-12 / 10$ & 192 & 0.84 & 6.14 & -0.58 & 4.76 & $35.48(0.00)$ \\
\hline Canada & $01 / 95-12 / 10$ & 192 & 0.98 & 6.25 & -0.76 & 5.47 & $67.20(0.00)$ \\
\hline France & $01 / 95-12 / 10$ & 192 & 0.59 & 6.04 & -0.45 & 4.01 & $14.79(0.00)$ \\
\hline Germany & $01 / 95-12 / 10$ & 192 & 0.62 & 6.86 & -0.49 & 4.70 & $30.89(0.00)$ \\
\hline Italy & $01 / 95-12 / 10$ & 192 & 0.45 & 6.85 & -0.16 & 3.58 & $3.50(0.17)$ \\
\hline Japan & $01 / 95-12 / 10$ & 192 & -0.18 & 5.58 & 0.13 & 2.79 & $0.93(0.63)$ \\
\hline Netherlands & $01 / 95-12 / 10$ & 192 & 0.56 & 6.17 & -0.86 & 4.94 & $53.51(0.00)$ \\
\hline Norway & $01 / 95-12 / 10$ & 192 & 0.88 & 7.99 & -0.85 & 5.85 & $87.90(0.00)$ \\
\hline Singapore & $01 / 95-12 / 10$ & 192 & 0.50 & 7.88 & -0.19 & 5.17 & $39.04(0.00)$ \\
\hline Spain & $01 / 95-12 / 10$ & 192 & 0.96 & 6.99 & -0.49 & 4.55 & $26.95(0.00)$ \\
\hline Switzerland & $01 / 95-12 / 10$ & 192 & 0.66 & 5.00 & -0.45 & 3.65 & $9.90(0.00)$ \\
\hline United Kingdom & $01 / 95-12 / 10$ & 192 & 0.43 & 4.63 & -0.44 & 4.80 & $31.95(0.00)$ \\
\hline United States & $01 / 95-12 / 10$ & 192 & 0.52 & 4.64 & -0.68 & 3.80 & $19.86(0.00)$ \\
\hline
\end{tabular}

correlation coefficients between developed and emerging stock markets is not confirmed. Table A.1 in the Appendix A shows correlation coefficients among international markets' excess returns. For the sample Jan 95-Dec 10 these coefficients are mostly positive. We find a negative correlation coefficient only between the Philippines and the US stock markets. Donadelli and Prosperi (2011) show that correlation coefficients between emerging and developed stock markets are increasing over time. Brooks and Del Negro (2002) claim that diversification across industries results to be more effective than diversification across countries.

Differences in risk and returns between developed and emerging markets are well captured (see Fig. 2.1). As expected, many emerging markets tend to be collocated on the north-east corner of the scatter-plot (i.e. they display higher average values of mean and standard deviation).

Among developed markets, the monthly average excess return is found to be less than $1.00 \%$ (see Tables 2.2 and 2.4 ). ${ }^{8}$ In contrast, the monthly average excess returns of emerging markets are generally above $1.00 \%$. For example, the Brazilian stock market provides a monthly average value equal to 2.50\% (Jan 88-Dec 10), 1.58\% (Jan 95-Dec 10) and 1.83\% (Jan 00Dec 10). Similarly, Indonesia delivers the following values: $1.68,1.24$ and $1.74 \%$.

To further investigate the differences in stock prices across international markets, we build six different portfolio stock indices. ${ }^{9}$ Each index is composed by countries belonging to the same macro-area. The following macro-areas are

\footnotetext{
${ }^{8}$ The highest performance is provided by the Canadian stock market (i.e. $0.98 \%$ for the sample Jan $95-$ Dec 10 ). “Good” performances are provided by the Australian and Norwegian stock markets over last 10 years, i.e. $1.04 \%$ and $1.13 \%$ respectively.

9 The composition of our equally weighted portfolios: Africa (Egypt, Morocco and South Africa); Asia (China, India, Indonesia, Malaysia, Philippines and South Korea); Eastern Europe (Czech Republic, Hungary, Poland, Russia and Turkey); Latin America (Argentina, Brazil, Chile, Colombia and Mexico); Developed (Australia, Canada, France, Germany, Italy, Japan, Netherlands, Norway, Singapore, Spain, Switzerland, United Kingdom and United States); Emerging: (Argentina, Brazil, Chile, China, Colombia, Czech Republic, Egypt, Hungary, India, Indonesia, Malaysia, Mexico, Morocco, Philippines, Poland, Russia, South Africa, Korea and Turkey).
} 
Table 2.5

Emerging stock markets-ERP descriptive statistics (common sample: Jan 95-Dec 10).

\begin{tabular}{|c|c|c|c|c|c|c|c|}
\hline Country (MSCI) & Sample & Obs. & Mean (\%) & St. Dev. (\%) & Skewness & Kurtosis & J. Bera \\
\hline Argentina & $01 / 95-12 / 10$ & 192 & 1.20 & 11.52 & -0.01 & 5.67 & $56.98(0.00)$ \\
\hline Brazil & $01 / 95-12 / 10$ & 192 & 1.58 & 11.28 & -0.43 & 4.20 & $17.33(0.00)$ \\
\hline Chile & $01 / 95-12 / 10$ & 192 & 0.77 & 6.78 & -0.65 & 5.53 & $64.84(0.00)$ \\
\hline China & $01 / 95-12 / 10$ & 192 & 0.46 & 10.74 & 0.55 & 5.53 & $60.89(0.00)$ \\
\hline Colombia & $01 / 95-12 / 10$ & 192 & 1.57 & 9.76 & -0.10 & 3.51 & $2.36(0.31)$ \\
\hline Czech Rep. & $01 / 95-12 / 10$ & 192 & 1.22 & 8.62 & -0.29 & 4.25 & $15.13(0.00)$ \\
\hline Egypt & $01 / 95-12 / 10$ & 192 & 1.68 & 9.65 & 0.52 & 5.13 & $44.99(0.00)$ \\
\hline Hungary & $01 / 95-12 / 10$ & 192 & 1.50 & 11.12 & -0.27 & 5.69 & $60.23(0.00)$ \\
\hline India & $01 / 95-12 / 10$ & 192 & 0.98 & 9.13 & 0.05 & 3.69 & $3.86(0.15)$ \\
\hline Indonesia & $01 / 95-12 / 10$ & 192 & 1.24 & 14.07 & 0.23 & 5.21 & $40.79(0.00)$ \\
\hline Malaysia & $01 / 95-12 / 10$ & 192 & 0.49 & 9.08 & 0.67 & 9.13 & $315.37(0.00)$ \\
\hline Mexico & $01 / 95-12 / 10$ & 192 & 1.17 & 8.62 & -0.85 & 4.78 & $48.56(0.00)$ \\
\hline Morocco & $01 / 95-12 / 10$ & 192 & 0.95 & 5.66 & 0.21 & 4.39 & $16.91(0.00)$ \\
\hline Philippines & $01 / 95-12 / 10$ & 192 & 0.04 & 9.35 & 0.35 & 5.45 & $51.79(0.00)$ \\
\hline Poland & $01 / 95-12 / 10$ & 192 & 1.03 & 11.00 & 0.07 & 4.21 & $11.79(0.00)$ \\
\hline Russia & $01 / 95-12 / 10$ & 192 & 2.41 & 16.56 & 0.19 & 4.90 & $29.87(0.00)$ \\
\hline South Africa & $01 / 95-12 / 10$ & 192 & 0.87 & 8.22 & -0.58 & 4.04 & $19.35(0.00)$ \\
\hline South Korea & $01 / 95-12 / 10$ & 192 & 0.99 & 12.26 & 1.04 & 8.10 & $242.60(0.00)$ \\
\hline Turkey & $01 / 95-12 / 10$ & 192 & 2.09 & 16.02 & 0.47 & 4.95 & $37.46(0.00)$ \\
\hline
\end{tabular}

Table 2.6

Developed stock markets-ERP descriptive statistics (common sample: Jan 00-Dec 10).

\begin{tabular}{|c|c|c|c|c|c|c|c|}
\hline Country & Sample & Obs. & Mean (\%) & St. Dev. (\%) & Skewness & Kurtosis & J. Bera \\
\hline Australia & $01 / 00-12 / 10$ & 132 & 1.04 & 6.64 & -0.59 & 4.62 & $22.01(0.00)$ \\
\hline Canada & $01 / 00-12 / 10$ & 132 & 0.83 & 6.58 & -0.64 & 4.95 & $30.06(0.00)$ \\
\hline France & $01 / 00-12 / 10$ & 132 & 0.18 & 6.50 & -0.42 & 3.75 & $6.99(0.03)$ \\
\hline Germany & $01 / 00-12 / 10$ & 132 & 0.29 & 7.50 & -0.39 & 4.20 & $11.39(0.00)$ \\
\hline Italy & $01 / 00-12 / 10$ & 132 & 0.07 & 6.82 & -0.37 & 3.88 & $7.21(0.03)$ \\
\hline Japan & $01 / 00-12 / 10$ & 132 & -0.24 & 5.23 & -0.04 & 2.85 & $0.15(0.93)$ \\
\hline Netherlands & $01 / 00-12 / 10$ & 132 & 0.19 & 6.77 & -0.76 & 4.49 & $24.78(0.00)$ \\
\hline Norway & $01 / 00-12 / 10$ & 132 & 1.13 & 8.55 & -0.83 & 5.38 & $46.24(0.00)$ \\
\hline Singapore & $01 / 00-12 / 10$ & 132 & 0.58 & 7.17 & -0.71 & 5.99 & $60.08(0.00)$ \\
\hline Spain & $01 / 00-12 / 10$ & 132 & 0.50 & 7.35 & -0.39 & 4.17 & $10.83(0.00)$ \\
\hline Switzerland & $01 / 00-12 / 10$ & 132 & 0.40 & 4.96 & -0.43 & 3.25 & $4.45(0.11)$ \\
\hline United Kingdom & $01 / 00-12 / 10$ & 132 & 0.09 & 5.13 & -0.32 & 4.33 & $12.02(0.00)$ \\
\hline United States & $01 / 00-12 / 10$ & 132 & -0.08 & 4.78 & -0.47 & 3.53 & $6.30(0.04)$ \\
\hline
\end{tabular}

Table 2.7

Emerging stock markets-ERP descriptive statistics (common sample: Jan 00-Dec 10).

\begin{tabular}{|c|c|c|c|c|c|c|c|}
\hline Country & Sample & Obs. & Mean (\%) & St. Dev. (\%) & Skewness & Kurtosis & J. Bera \\
\hline Argentina & $01 / 00-12 / 10$ & 132 & 1.30 & 12.29 & 0.09 & 5.52 & $35.19(0.00)$ \\
\hline Brazil & $01 / 00-12 / 10$ & 132 & 1.83 & 10.80 & -0.41 & 3.72 & $6.57(0.04)$ \\
\hline Chile & $01 / 00-12 / 10$ & 132 & 1.27 & 6.32 & -0.54 & 5.47 & $40.07(0.00)$ \\
\hline China & $01 / 00-12 / 10$ & 132 & 0.90 & 8.62 & -0.49 & 3.25 & $5.54(0.06)$ \\
\hline Colombia & $01 / 00-12 / 10$ & 132 & 2.65 & 9.46 & -0.33 & 3.26 & $2.76(0.25)$ \\
\hline Czech Rep. & $01 / 00-12 / 10$ & 132 & 1.91 & 8.55 & -0.18 & 4.28 & $9.72(0.00)$ \\
\hline Egypt & $01 / 00-12 / 10$ & 132 & 1.56 & 10.10 & 0.25 & 4.76 & $18.48(0.00)$ \\
\hline Hungary & $01 / 00-12 / 10$ & 132 & 1.08 & 10.51 & -0.61 & 4.97 & $29.43(0.00)$ \\
\hline India & $01 / 00-12 / 10$ & 132 & 1.38 & 9.31 & -0.10 & 4.19 & $8.07(0.02)$ \\
\hline Indonesia & $01 / 00-12 / 10$ & 132 & 1.74 & 11.02 & -0.34 & 3.95 & $7.57(0.02)$ \\
\hline Malaysia & $01 / 00-12 / 10$ & 132 & 0.84 & 5.79 & -0.25 & 3.33 & $1.98(0.37)$ \\
\hline Mexico & $01 / 00-12 / 10$ & 132 & 1.19 & 7.41 & -0.70 & 4.56 & $24.19(0.00)$ \\
\hline Morocco & $01 / 00-12 / 10$ & 132 & 0.85 & 6.11 & 0.16 & 4.11 & $7.28(0.03)$ \\
\hline Philippines & $01 / 00-12 / 10$ & 132 & 0.54 & 8.00 & -0.13 & 3.16 & $0.50(0.78)$ \\
\hline Poland & $01 / 00-12 / 10$ & 132 & 1.05 & 10.35 & -0.10 & 3.46 & $1.42(0.49)$ \\
\hline Russia & $01 / 00-12 / 10$ & 132 & 1.66 & 11.19 & -0.16 & 3.97 & $5.71(0.06)$ \\
\hline South Africa & $01 / 00-12 / 10$ & 132 & 1.26 & 8.01 & -0.46 & 3.16 & $4.84(0.09)$ \\
\hline South Korea & $01 / 00-12 / 10$ & 132 & 1.14 & 9.74 & 0.01 & 3.11 & $0.07(0.97)$ \\
\hline Turkey & $01 / 00-12 / 10$ & 132 & 1.38 & 15.12 & -0.10 & 3.37 & $0.98(0.61)$ \\
\hline
\end{tabular}


Table 2.8

Macro stock markets_ERP descriptive statistics (common sample: Jan 95-Dec 10).

\begin{tabular}{|c|c|c|c|c|c|c|c|}
\hline Country (MSCI) & Sample & Obs. & Mean (\%) & St. Dev. (\%) & Skewness & Kurtosis & J. Bera \\
\hline Africa & $01 / 95-12 / 10$ & 192 & 1.03 & 6.20 & -0.41 & 4.99 & $36.94(0.00)$ \\
\hline Asia & $01 / 95-12 / 10$ & 192 & 0.47 & 8.38 & -0.25 & 4.81 & $28.18(0.00)$ \\
\hline Eastern Europe & $01 / 95-12 / 10$ & 192 & 1.24 & 10.01 & -0.35 & 5.23 & $43.53(0.00)$ \\
\hline Latin America & $01 / 95-12 / 10$ & 192 & 1.03 & 7.75 & -0.97 & 5.76 & $91.14(0.00)$ \\
\hline Emerging (All) & $01 / 95-12 / 10$ & 192 & 0.91 & 7.32 & -1.01 & 6.12 & $110.94(0.00)$ \\
\hline Developed (All) & $01 / 95-12 / 10$ & 192 & 0.49 & 5.30 & -0.83 & 5.41 & $68.12(0.00)$ \\
\hline
\end{tabular}

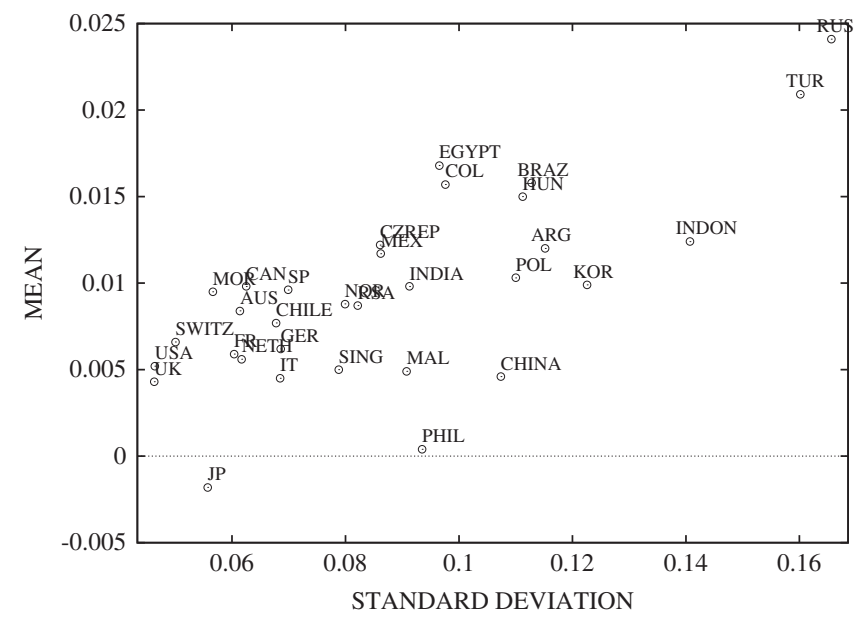

Fig. 2.1. International stock markets: mean vs. standard deviation (sample: Jan 95-Dec 10).

Table 2.9

Macro stock markets-ERP descriptive statistics (common sample: Jan 00-Dec 10).

\begin{tabular}{|c|c|c|c|c|c|c|c|}
\hline Country & Sample & Obs. & Mean (\%) & St. Dev. (\%) & Skewness & Kurtosis & J. Bera \\
\hline Africa & $01 / 00-12 / 10$ & 132 & 1.15 & 6.76 & -0.55 & 4.82 & $24.83(0.00)$ \\
\hline Asia & $01 / 00-12 / 10$ & 132 & 1.01 & 7.07 & -0.55 & 4.77 & $23.93(0.00)$ \\
\hline Eastern Europe & $01 / 00-12 / 10$ & 132 & 1.03 & 9.43 & -0.56 & 3.93 & $11.72(0.00)$ \\
\hline Latin America & $01 / 00-12 / 10$ & 132 & 1.26 & 7.46 & -0.79 & 5.33 & $43.56(0.00)$ \\
\hline Emerging (All) & $01 / 00-12 / 10$ & 132 & 1.15 & 7.17 & -0.87 & 5.54 & $52.39(0.00)$ \\
\hline Developed (All) & $01 / 00-12 / 10$ & 132 & 0.32 & 5.80 & -0.73 & 4.78 & $29.28(0.00)$ \\
\hline
\end{tabular}

considered: Africa, Asia, Eastern Europe, Latin America, Emerging (All) and Developed. Countries' stock indices are equally weighted (see Eq. (2.2)).

$$
\text { Portfolio } j, t=\frac{1}{N} \sum_{i}^{N} M S C I T R I_{i, t}
$$

where the MSCI TRI $i_{t} t$ is the specific country stock index, $N$ is the number of countries and $j$ indicates the macro-area. Distributional characteristics are shown in Tables 2.8 and 2.9. Salomons and Grootveld (2003) argue that this procedure reduces the impact of country specific issues. For the sample Jan 95-Dec 10, the emerging portfolio shows both higher excess return (i.e. $0.91 \%$ vs. $0.49 \%$ ) and volatility (i.e. $7.32 \%$ vs. $5.30 \%$ ) than the developed portfolio. If the sample Jan $00-$ Dec 10 is considered, the performance gap is exacerbated.

A general decline in developed stock markets' performances over the last ten years is also evident. Jagannathan et al. (2000) demonstrate that the US equity premium has declined significantly during the last three decades. ${ }^{10}$ Table 2.6 shows the distributional characteristics of developed ERPs over the last decade. For a large number of developed stock markets

\footnotetext{
${ }^{10}$ US stock market performance over different sub-samples (i.e. US MSCI Total Return Index): - 0.081\% (Jan 00-Dec 10); 0.201\% (Jan 02-Dec 10); 0.167\% (Jan05-Dec 10); - 0.014\% (Jan 07-Dec 10). Developed stock market performance over different sub-samples (i.e. Developed MSCI Total Return Index): 0.32\% (Jan 00-Dec 10); 0.75\% (Jan 02-Dec 10); 0.63\% (Jan 05-Dec 10); 0.20\% (Jan 07-Dec 10).
} 
the decline is evident. Moreover, the US and Japan display negative average excess returns, $-0.08 \%$ and $-0.24 \%$ respectively.

In line with Bekaert et al. (1998) and Salomons and Grootveld (2003), we observe the presence of high kurtosis in developed stock markets. We stress also that the excess returns of the developed portfolio are negative skewed. Scott and Horvath (1980) claim that in presence of negative skewness, investors should be compensated. Our empirical results do not confirm the positive relationship between negative skewness and compensation. In general, excess returns are not normally distributed. Fat tails and asymmetries are well captured by our portfolios' excess returns kernel density estimations (see Figs. A1 and A2).

Domowitz et al. (1997a,b) claim that interest in emerging markets, has grown rapidly in the last recent years as investors seek higher returns and international diversification. Henry (2000) argues that stock market liberalization may reduce the liberalizing country's cost of equity capital by allowing for risk sharing between domestic and foreign agents. In many markets, foreign investors must contend with investment barriers in the form of restrictions on foreign equity ownership. He also claims that, such investment barriers are of particular interest, because they place limits on the percentage of a firm's equity that foreign investors can hold, possibly inducing capital market segmentation.

In addition, emerging markets are generally small and illiquid. In the remaining part of the paper, we try to answer the following question: can emerging stock markets' illiquidity explain the observed extra premium?

\section{Why do we observe extra premia in emerging markets?}

\subsection{The CAPM: Estimation results (a simple one factor model)}

Do emerging stock markets really provide abnormal returns? To address this question, we first adopt the SharpeLintner (1964) version of the CAPM. In line with Black et al. (1972), the following country-by-country regression is considered:

$$
E R P_{i, t}=\alpha_{i}+\beta_{i, m}\left(E R P_{m, t}\right)+\varepsilon_{i, t}
$$

where $E R P_{i, t}=$ excess return of the $i_{t h}$ stock market, $E R P_{m, t}=$ excess return of the market portfolio, $\beta_{i, m}=\left(\operatorname{cov}\left(R_{i} ; R_{m}\right) /\right.$ $\left.\operatorname{var}\left(R_{m}\right)\right)=$ beta value for stock $i$ relative to the market portfolio, $\alpha_{i}=$ Jensen's alpha.

If the Sharpe-Lintner (1964) version of the CAPM holds, it must be that $\alpha_{i}=0$ in Eq. (3.1) (i.e. the excess return of asset $i$ is equal to the quantity of risk of this asset times the price of risk). The intercept is referred to as Jensen's alpha. ${ }^{11}$ The coefficient indicates whether on average the observed returns are larger (or smaller) than the value consistent with the market model (i.e. CAPM). While predicting the appropriate risk-adjusted return of a stock, the market model might fail (i.e. a discrepancy emerges when stocks which are perceived to be more risky provide higher expected returns than those predicted by the model). Our goal is to assess whether or not the aforementioned discrepancy is caused by stock market illiquidity.

According to Eq. (3.1), we test the statistical significance of the estimated intercept. We compute standard errors robustly using the methodology developed by Newey and West (1994). Thus, our standard errors are corrected both for autocorrelation and heteroskedasticity. Presence of autocorrelation in the residuals is confirmed by Fig. A7.

The country-by-country CAPM is tested over the two different common samples. Empirical estimation results of the one-factor model are illustrated in Table 3.1. Beta coefficients are statistically different from zero at $1 \%$ level, both for developed and emerging stock markets. Across developed stock markets the CAPM is rarely violated (i.e. the null hypothesis of $\alpha_{i}=0$ is rarely rejected). We find that only the Canadian stock market has a significant and different from zero alpha at $5 \%$ confidence level (sample: Jan 95-Dec 10). In addition, alphas are found to be positive and statistically different from zero at $1 \%$ level in the following stock markets: Australia, Canada and Norway (sample: Jan 00-Dec 10). ${ }^{12}$ The null is rejected at 5\% level for the developed portfolio (sample: Jan 00-Dec 10).

Country-by-country CAPM estimates on emerging stock markets are presented in Table 3.2. The CAPM is sporadically violated (sample: Jan 95-Dec 10). In contrast, it sporadically holds for the sub-sample Jan 00-Dec 10. In the last 15 years, we show that emerging markets' alphas are statistically different from zero at $10 \%$ significant level only in the following countries: Colombia, Egypt, Morocco and Africa. For the sample Jan 00-Dec 10, the null hypothesis of $\alpha_{i}=0$ is mostly rejected at either 10, 5 or $1 \%$ levels. The CAPM holds only in the following countries: Argentina, Morocco and Philippines.

We also find that $r$-squared values between developed and emerging markets are different. Moving from the sample Jan 95-Dec 10 to the sample Jan 00-Dec 10, our one-factor predictions tend to be more accurate, both in mature and young stock markets. For example, in the Emerging and Asia portfolios the $r$-squared values move from 0.64 to 0.73 and from 0.44 to 0.57 respectively. These results have a simple interpretation, i.e. once we perform our estimates using the sample Jan 00 -Dec 10, we account for a period where average excess returns between emerging and developed stock markets are highly correlated.

\footnotetext{
11 The Jensen's alpha is a value extensively employed in finance to evaluate the performance of assets and fund managers.

12 Recall that superior performances in the Australian and Norwegian stock markets over the sample Jan 00-Dec 10 are observed.
} 
Table 3.1

Developed markets (one-factor estimation results).

\begin{tabular}{|c|c|c|c|c|c|c|c|c|}
\hline MSCI TRI & Period & $\alpha$ & $\beta$ & $R^{2}$ & Period & $\alpha$ & $\beta$ & $R^{2}$ \\
\hline Australia & $01 / 95-12 / 10$ & $0.0041[0.0031]$ & $1.0974^{* * * *}[0.086]$ & 0.6718 & $01 / 00-12 / 10$ & $0.0101^{* * * *}[0.0026]$ & $1.1638^{* * * * *}[0.0836]$ & 0.7374 \\
\hline Canada & $01 / 95-12 / 10$ & $0.0053^{* * *}[0.0026]$ & $1.1545^{* * * *}[0.0656]$ & 0.7176 & $01 / 00-12 / 10$ & $0.008^{* * * *}[0.0027]$ & $1.1535^{\text {***** }}[0.0756]$ & 0.7370 \\
\hline France & $01 / 95-12 / 10$ & $0.0013[0.0015]$ & $1.1709^{* * * *}[0.0488]$ & 0.7902 & $01 / 00-12 / 10$ & $0.0015[0.0017]$ & $1.2235^{* * * * *}[0.0399]$ & 0.8499 \\
\hline Germany & $01 / 95-12 / 10$ & $0.0011[0.0019]$ & $1.2991^{* * * *}[0.0828]$ & 0.7546 & $01 / 00-12 / 10$ & $0.0026[0.0023]$ & $1.3860^{* * * *}[0.0743]$ & 0.8189 \\
\hline Italy & $01 / 95-12 / 10$ & $0.0001[0.0029]$ & $1.1325^{* * * *}[0.0808]$ & 0.5743 & $01 / 00-12 / 10$ & $0.0005[0.0027]$ & $1.1791^{* * * *}[0.0700]$ & 0.7171 \\
\hline Japan & $01 / 95-12 / 10$ & $-0.0050[0.0035]$ & $0.8243^{* * * *}[0.0699]$ & 0.4600 & $01 / 00-12 / 10$ & $-0.0025[0.0033]$ & $0.7526^{* * * *}[0.0649]$ & 0.4977 \\
\hline Netherlands & $01 / 95-12 / 10$ & $0.0010[0.0018]$ & $1.1851^{* * * *}[0.0682]$ & 0.7757 & $01 / 00-12 / 10$ & $0.0017[0.002]$ & $1.257^{* * * * *}[0.0582]$ & 0.8285 \\
\hline Norway & $01 / 95-12 / 10$ & $0.0036[0.004]$ & $1.345^{* * * *}[0.1262]$ & 0.5956 & $01 / 00-12 / 10$ & $0.011^{* * * *}[0.0039]$ & $1.4628^{* * * * *}[0.1303]$ & 0.7021 \\
\hline Singapore & $01 / 95-12 / 10$ & $0.0003[0.005]$ & $1.2022^{* * * *}[0.1103]$ & 0.4900 & $01 / 00-12 / 10$ & $0.0056[0.0036]$ & $1.1188^{* * * *}[0.1027]$ & 0.5843 \\
\hline Spain & $01 / 95-12 / 10$ & $0.0048 *[0.0028]$ & $1.2308^{* * * *}[0.0707]$ & 0.6514 & $01 / 00-12 / 10$ & $0.0048[0.0036]$ & $1.2585^{* * * *}[0.0603]$ & 0.7042 \\
\hline Switzerland & $01 / 95-12 / 10$ & $0.0034[0.0021]$ & $0.8266^{* * * * k}[0.0481]$ & 0.5757 & $01 / 00-12 / 10$ & $0.0038 *[0.0020]$ & $0.8336^{* * * * *}[0.0538]$ & 0.6772 \\
\hline UK & $01 / 95-12 / 10$ & $0.0008[0.0016]$ & $0.9001^{* * * *}[0.0491]$ & 0.7943 & $01 / 00-12 / 10$ & $0.0007[0.0016]$ & $0.9666^{* * * * *}[0.0400]$ & 0.8513 \\
\hline US & $01 / 95-12 / 10$ & $0.0015[0.0013]$ & $0.9605^{* * * *}[0.0269]$ & 0.9017 & $01 / 00-12 / 10$ & $-0.0010[0.0001]$ & $0.9448^{* * * * *}[0.0236]$ & 0.9384 \\
\hline Developed & $01 / 95-12 / 10$ & $0.0006[0.0011]$ & $1.1078^{* * * *}[0.0381]$ & 0.9194 & $01 / 00-12 / 10$ & $0.0029^{* *}[0.0012]$ & $1.1452^{* * * * *}[0.0334]$ & 0.9347 \\
\hline
\end{tabular}

Standard errors (in square brackets) are computed using the procedure described in Newey and West (1994).

* Significantly different from zero at the $10 \%$ levels, respectively.

** Significantly different from zero at the $5 \%$ levels, respectively.

*** Significantly different from zero at the $1 \%$ levels, respectively.

As discussed above, we estimate the alphas directly from a simple one-factor model. The alpha is often interpreted as a riskadjusted measure of performance, which evaluates the ability of the portfolio manager in selecting assets with superior performance. Our estimates suggest that the emerging excess returns are larger than their equilibrium values consistent with the amount of systemic risk. In other words, the stock indices are located above the security market line (i.e. undervalued stock). Fig. 3.1 shows the locations of the portfolios in the beta-excess returns space. As expected, they are located far above the security market line.

In Figs. A3 and A4 we plot the realized average excess returns (on the vertical axis) against predicted average excess returns (on the horizontal axis). The presence of positive alphas is evident in both samples. On average predicted average excess returns fall far below the average values. In Fig. A5 we also plot the ratios between the predicted and the actual excess returns. It shows that a large part of the actual excess returns is explained by the intercept. Where do such superior ex-post performances come from? Can illiquidity explain our empirical results?

To make stronger our empirical analysis the Gibbons et al. (1989) testing procedure is implemented. Typically, timeseries studies of the CAPM are conducted by employing data on a group of stocks, such as securities and portfolios of securities. In this way, rather than conducting tests on individual assets, we run tests which investigate whether the CAPM holds for the group of assets as a whole. This is considered a superior method to test the validity of the CAPM in that the resulting test possesses larger power. The system of $N$ one-factor regressions can be written in the following form:

$$
\underset{(N \cdot 1)}{\boldsymbol{E R P}_{t}}=\underset{(N \cdot 1)}{\alpha}+\underset{(N \cdot 1)}{\beta} \boldsymbol{E R P}_{m, t}+\underset{(N \cdot 1)}{\varepsilon_{t}}
$$

where $\boldsymbol{E R} \boldsymbol{P}_{t}, \boldsymbol{\alpha}, \boldsymbol{\beta}$ and $\boldsymbol{\varepsilon}_{t}$ are (N 1) vectors. Similarly to the univariate CAPM version, Eq. (3.2) holds if all the alphas are jointly equal to zero. To estimate such system and run a join test on the significance of the $N$ stocks' alphas, we assume that the excess returns are jointly normally distributed. Under this assumption the vector of alphas converges asymptotically to a multi-normal distribution and under the null hypothesis that all alphas are jointly equal to zero, consistently with the standard CAPM, the statistic is asymptotically distributed as a Central Chi-Square random variable with $N$ degrees of freedom. Replacing the unobservable quantities with their sample counterparts, under the null we get an asymptotic test of the overall significance of the vector of Jensen's alphas. Eq. (3.3) allows us to test the null $H_{0}: \alpha=0$ against the alternative $H_{1}: \alpha \neq 0$ (Fig. 3.2 ). ${ }^{13}$

$$
\xi_{0}^{\chi}=T\left(1+\frac{E R P_{t}^{2}}{\hat{\sigma}_{m}^{2}}\right)^{-1} \hat{\alpha}^{\prime} \hat{\Sigma} \hat{\alpha} \stackrel{d}{\rightarrow} \chi^{2}(N)
$$

Estimation results of the multivariate test are illustrated in Table 3.3. The test is performed for three different portfolios: emerging, developed and global. ${ }^{14}$ As suggested by Harvey (1995) the multivariate test of Gibbons et al. (1989) provides evidence against the null hypothesis that the intercepts are zero for 18 countries at the 1 and $5 \%$ confidence levels. The result holds only for the sample Jan 00-Dec 10. We stress again that the time-varying nature of the risk factors cannot be underestimated.

Our empirical studies confirm the CAPM's weakness in predicting emerging stock prices. Based on the country-by-country analysis we find that emerging intercepts are statistically different from zero. In addition, we show that they are strictly positive. Our results imply that emerging stock markets' average excess returns largely exceed the levels predicted by the CAPM.

\footnotetext{
${ }^{13}$ For a limited sample $T$ assuming normality of the residuals the following $F$ statistic holds: $\xi_{0}^{F}=\frac{T-N-1}{N}\left(1+\frac{E R P_{t}^{2}}{\hat{\sigma}_{m}^{2}}\right)^{-1} \hat{\alpha}^{\prime} \hat{\Sigma} \hat{\alpha} \sim F(N, T-N-1)$

14 The global portfolio is composed by all countries' excess returns.
} 
Table 3.2

Emerging markets and portfolios (one-factor estimation results).

\begin{tabular}{|c|c|c|c|c|c|c|c|c|}
\hline MSCI TRI & Period & $\alpha$ & $\beta$ & $R^{2}$ & Period & $\alpha$ & $\beta$ & $R^{2}$ \\
\hline Argentina & $01 / 95-12 / 10$ & $0.0073[0.0062]$ & $1.202^{* * * * *}[0.1788]$ & 0.2292 & $01 / 00-12 / 10$ & $0.0128[0.0089]$ & $1.142^{\text {**** }}[0.2289]$ & 0.2071 \\
\hline Brazil & $01 / 95-12 / 10$ & $0.0093[0.0061]$ & $1.6731^{* * * *}[0.1251]$ & 0.4628 & $01 / 00-12 / 10$ & $0.018^{* * * k}[0.0055]$ & $1.687^{* * * *}[0.1591]$ & 0.5853 \\
\hline Chile & $01 / 95-12 / 10$ & $0.0043[0.0046]$ & $0.8738^{* * * k}[0.1016]$ & 0.3496 & $01 / 00-12 / 10$ & $0.0126^{\text {***k }}[0.0039]$ & $0.8397^{* * * *}[0.1112]$ & 0.4241 \\
\hline China & $01 / 95-12 / 10$ & $0.0001[0.0063]$ & $1.1528^{* * * * k}[0.1434]$ & 0.2425 & $01 / 00-12 / 10$ & $0.0088[0.0054]$ & $1.1789^{* * * *}[0.1283]$ & 0.4485 \\
\hline Colombia & $01 / 95-12 / 10$ & $0.012 *[0.0078]$ & $0.8158^{* * * *}[0.172]$ & 0.1471 & $01 / 00-12 / 10$ & $0.0263^{* * * * k}[0.0069]$ & $0.9716^{* * * *}[0.1403]$ & 0.2534 \\
\hline Czech Rep. & $01 / 95-12 / 10$ & $0.0085[0.0061]$ & $0.9529^{* * * *}[0.2068]$ & 0.2574 & $01 / 00-12 / 10$ & $0.0188^{* * * * k}[0.0057]$ & $1.1074^{* * * *}[0.1729]$ & 0.4026 \\
\hline Egypt & $01 / 95-12 / 10$ & $0.0135^{*}[0.0089]$ & $0.8431^{* * * *}[0.2251]$ & 0.1606 & $01 / 00-12 / 10$ & $0.0154 *[0.009]$ & $0.9747^{* * * *}[0.2171]$ & 0.2237 \\
\hline Hungary & $01 / 95-12 / 10$ & $0.0088[0.0059]$ & $1.5806^{* * * *}[0.1937]$ & 0.4252 & $01 / 00-12 / 10$ & $0.0105^{* * * * k}[0.0062]$ & $1.5559 * * * ; 0.1861]$ & 0.5257 \\
\hline India & $01 / 95-12 / 10$ & $0.0057[0.0054]$ & $1.053^{* * * *}[0.1906]$ & 0.2797 & $01 / 00-12 / 10$ & $0.0135^{* * *}[0.0057]$ & $1.2549 * * * ; 0.1553]$ & 0.4358 \\
\hline Indonesia & $01 / 95-12 / 10$ & $0.0066[0.0114]$ & $1.491^{* * * * k}[0.2586]$ & 0.2364 & $01 / 00-12 / 10$ & $0.0171^{* * *}[0.0080]$ & $1.2439 * * * ; 0.2289]$ & 0.3056 \\
\hline Malaysia & $01 / 95-12 / 10$ & $0.0017[0.0084]$ & $0.8308^{* * * *}[0.166]$ & 0.1762 & $01 / 00-12 / 10$ & $0.0083^{* * *}[0.0045]$ & $0.583029^{* * * *}[0.0933]$ & 0.2432 \\
\hline Mexico & $01 / 95-12 / 10$ & $0.0066[0.0041]$ & $1.3349^{* * * * k}[0.0862]$ & 0.5051 & $01 / 00-12 / 10$ & $0.0117^{\text {***k }}[0.0031]$ & $1.2413^{* * * * k}[0.0794]$ & 0.6731 \\
\hline Morocco & $01 / 95-12 / 10$ & $0.0085^{*}[0.0048]$ & $0.2588^{* * * *}[0.1218$ & 0.0440 & $01 / 00-12 / 10$ & $0.0084^{*}[0.005]$ & $0.4218^{* * * * k}[0.1336]$ & 0.1143 \\
\hline Philippines & $01 / 95-12 / 10$ & $-0.0034[0.007]$ & $0.9808^{* * * *}[0.1818]$ & 0.2314 & $01 / 00-12 / 10$ & $0.0052[0.006]$ & $0.788^{* * * *}[0.1185]$ & 0.2330 \\
\hline Poland & $01 / 95-12 / 10$ & $0.0044[0.004]$ & $1.5176^{* * * *}[0.1391]$ & 0.4006 & $01 / 00-12 / 10$ & $0.0102^{* * *}[0.0048]$ & $1.5289^{* * * *}[0.121]$ & 0.5236 \\
\hline Russia & $01 / 95-12 / 10$ & $0.0170[0.011]$ & $1.8214^{* * * * *}[0.2591]$ & 0.2545 & $01 / 00-12 / 10$ & $0.0163^{* * *}[0.0067]$ & $1.5053^{* * * *}[0.1747]$ & 0.4342 \\
\hline South Africa & $01 / 95-12 / 10$ & $0.0039[0.0045]$ & $1.2342^{* * * *}[0.1084]$ & 0.4738 & $01 / 00-12 / 10$ & $0.0123^{\text {***k }}[0.0042]$ & $1.23^{* * * * k}[0.0942]$ & 0.5653 \\
\hline South Korea & $01 / 95-12 / 10$ & $0.0040[0.0087]$ & $1.5229^{* * * *}[0.119]$ & 0.3247 & $01 / 00-12 / 10$ & $0.011^{*}[0.006]$ & $1.4876^{* * * *}[0.09]$ & 0.5603 \\
\hline Turkey & $01 / 95-12 / 10$ & $0.0135[0.0071]$ & $1.9142^{* * * * k}[0.2393]$ & 0.3004 & $01 / 00-12 / 10$ & $0.0134^{*}[0.0077]$ & $1.9779 * * * ; 0.2521]$ & 0.4107 \\
\hline Asia & $01 / 90-12 / 10$ & ] & $1.2082^{* * * *}[0.1344]$ & 0.4372 & $01 / 00-12 / 10$ & $0.0099^{* *}[0.0044]$ & $1.0945^{* * * *}[0.1124]$ & 0.5745 \\
\hline Latin America & $01 / 95-12 / 10$ & $0.0053[0.004]$ & $1.2727^{* * * * k}[0.0731]$ & 0.5680 & $01 / 00-12 / 10$ & $0.0123^{* * * * k}[0.0033]$ & $1.2447^{* * * *}[0.0890]$ & 0.6673 \\
\hline Africa & $01 / 95-12 / 10$ & $0.0072 *[0.0046]$ & $0.7867^{* * * *}[0.1347]$ & 0.3383 & $01 / 00-12 / 10$ & $0.0114^{* * * *}[0.0050]$ & $0.8987^{* * * * *}[0.1308]$ & 0.4236 \\
\hline Eastern Eu & $01 / 95-12 / 10$ & $0.0063[0.0047]$ & $1.5897^{* * * *}[0.1094]$ & 0.5309 & $01 / 00-12 / 10$ & $0.010^{* * *}[0.0042]$ & $1.558^{* * * *}[0.1174]$ & 0.6551 \\
\hline Emerging & $01 / 95-12 / 10$ & $0.0041[0.0041]$ & $1.2763^{* * * k}[0.0724]$ & 0.6404 & $01 / 00-12 / 10$ & $0.0113^{\text {***kk }}[0.0030]$ & $1.2503^{* * * *}[0.0847]$ & 0.7299 \\
\hline
\end{tabular}

Standard errors (in square brackets) are computed using the procedure described in Newey and West (1994).

* Significantly different from zero at the $10 \%$ levels, respectively.

** Significantly different from zero at the 5\% levels, respectively.

*** Significantly different from zero at the $1 \%$ levels, respectively.

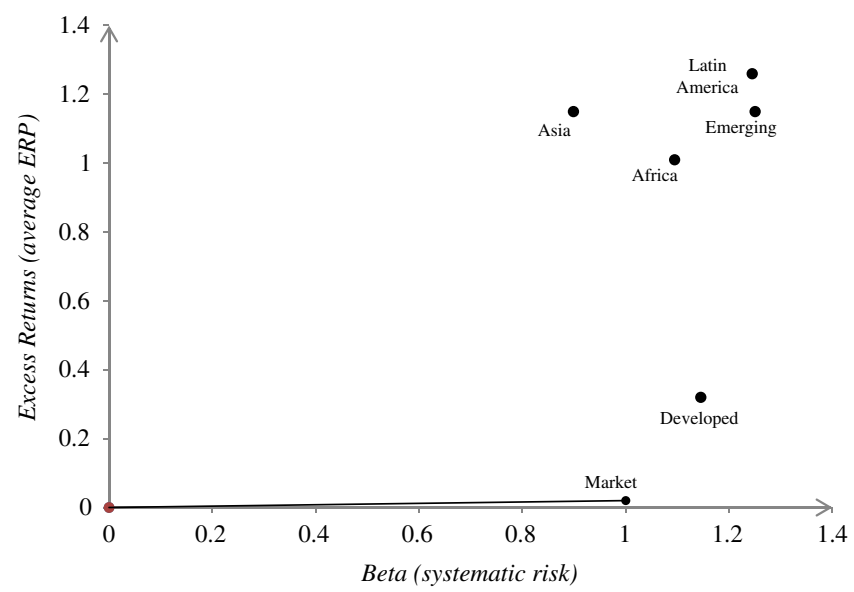

Fig. 3.1. Portfolios-security market line (sample: Jan 00-Dec 10).

Next section is aimed at explaining this empirical puzzle. We specifically try to give an answer to the following question: do local liquidity factors validate the model and predict emerging markets' premia? In estimating the CAPM another puzzle arises. Beta's estimates over the two different estimation periods are found to be different, especially in emerging markets. In particular, in most of the cases the estimated betas for the sample Jan 00-Dec 10 results to be larger than the those estimated for the sample Jan 95-Dec 10. We confirm the time-varying nature of international stock prices, as well as the time variation of the risk factors. ${ }^{15}$ To capture the risk factor's time variations, we estimate the betas using a rolling window procedure. Rolling estimations are implemented for our 6 macro-portfolios. ${ }^{16}$ Results are presented in

\footnotetext{
${ }^{15}$ See Harvey (1995), Bekaert and Harvey (1995), Bekaert and Harvey (1997), Salomons and Grootveld (2003), Bekaert and Harvey (2003a), Bekaert et al. (2007) and Donadelli and Prosperi (2011), among others.

${ }^{16}$ In the five-years rolling window estimates of the beta we simply run the OLS estimate on a five year window starting from the sample Jan 93-Dec 96 to the sample Jan 07-Dec 10. In Fig. 3.1 all our betas are normalized with respect to the final estimate in the sample Jan 07-Dec 10.
} 


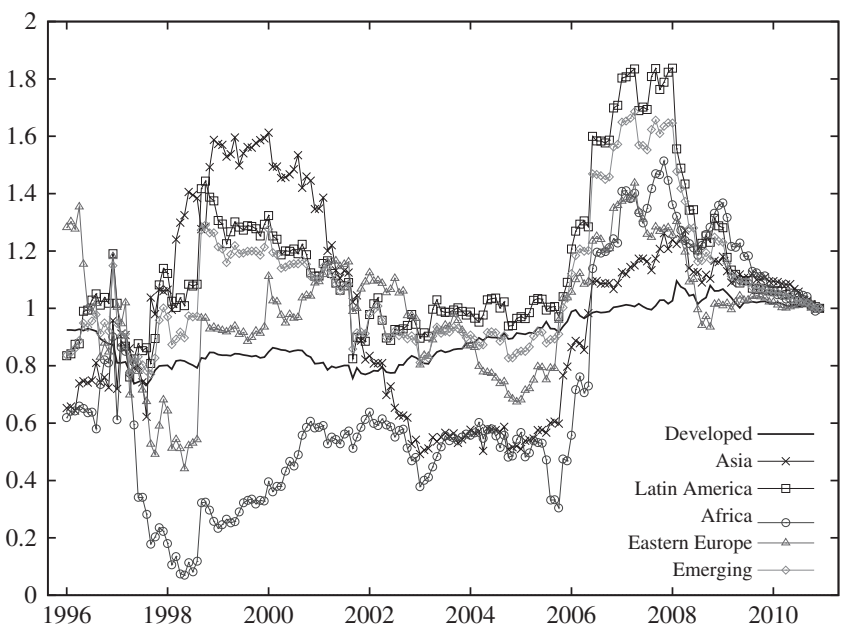

Fig. 3.2. Normalized five-years rolling window estimates of the beta.

Table 3.3

Gibbons, Ross and Shanken (1989) multivariate test ( $p$-values are reported in parentheses).

\begin{tabular}{|c|c|c|c|c|}
\hline \multirow[t]{2}{*}{ Portfolio } & \multicolumn{2}{|l|}{ Jan 95-Dec 10} & \multicolumn{2}{|l|}{ Jan 00-Dec 10} \\
\hline & Chi-Test & F-Test & Chi-Test & F-Test \\
\hline Global & $57.9308(0.0033)$ & $1.4992(0.0549)$ & $84.5705(0.0000)$ & $1.9821(0.0031)$ \\
\hline Developed & $32.2245(0.0022)$ & $2.2981(0.0078)$ & $42.3814(0.0001)$ & $2.9143(0.0011)$ \\
\hline Emerging & $16.2342(0.6416)$ & $0.7654(0.7452)$ & $38.1322(0.0057)$ & $1.7029(0.0457)$ \\
\hline
\end{tabular}

Fig. 3.1. We find that the quantity of risk is strongly time-varying. We argue that the time variations are much more evident in the emerging world. The systematic risk structure of the developed portfolio appears to be stable through time. We claim that a "beta puzzle" takes place. The puzzle is discussed and studied extensively in Section 6.

\section{The alpha puzzle}

\subsection{Does liquidity matter?}

In the last two decades emerging stock markets have captured the attention of a large number of international private and institutional investors, both to achieve higher returns and to diversify portfolio risk. We claim that positions in emerging stock markets are subject to several risks. Domowitz et al. (1997a,b) argue that in many emerging markets, international investors must contend with investment barriers in the form of restrictions on foreign equity ownership. Eun and Janakiramanan (1986) study the problem of the restrictions imposed on foreign equity holdings in 16 countries.

Harvey (1995) suggests that, in completely segmented markets where a one-factor model characterizes asset returns, expected returns are priced with respect to the covariance with the national market portfolio rather than the world market portfolio. In completely integrated capital markets with purchasing power parity, the covariance with the world portfolio determines the cross-section of expected returns; therefore a standard one-factor asset pricing model might be sufficient. According to our empirical results it should be reasonable to assume that some of these markets are not fully financially integrated. As a consequence local factors should be relevant for emerging stock prices. Harvey (1995) claims that the degree and effect of the segmentation is not obvious. In a fully segmented capital market, covariance with a global risk factor might be important. It is unlikely that the national economy is completely independent of the world economy. Donadelli and Prosperi (2011), confirm the role of macro risk factors in affecting "isolated markets". Using a simple twofactor model, Harvey (1995) shows that foreign exchange risk factor has some explanatory power, supporting the idea that emerging markets are segmented. He also shows that the validity of the two-factor model is not preserved. He claims that the main reason for the unconditional CAPM's failure is that the conditional risk exposures are constant over time, suggesting that exposures may be time varying.

It is largely accepted that liquidity measures are important in stock return predictability, especially in those markets where restrictions imposed on foreign equity holdings still take place. Domowitz et al. (1997a,b) claim that the simplest explanation for the existence of stock premia is the liquidity hypothesis. In a simple model, based on the Mexican stock market, they show that stock price premia for unrestricted shares (i.e. open to all international investors) reflects the lower transaction costs and greater liquidity relative to the often inactively traded restricted shares (i.e. open only to Mexicans). 
Table 4.1

S\&P IFCI-emerging markets and portfolios (one-factor estimation results).

\begin{tabular}{|c|c|c|c|c|c|c|c|c|}
\hline S\&P IFCI & Period & $\alpha$ & $\beta$ & $R^{2}$ & Period & $\alpha$ & $\beta$ & $R^{2}$ \\
\hline Argentina & $01 / 95-08 / 09$ & $0.0037[0.0068]$ & $1.3214^{* * * *}[0.1631]$ & 0.2805 & $01 / 00-08 / 09$ & $0.009[0.009]$ & $1.2833^{\text {****k }}[0.1886]$ & 0.2686 \\
\hline Brazil & $01 / 95-12 / 10$ & $0.0099 *[0.0062]$ & $1.7019^{* * * * *}[0.1282]$ & 0.4704 & $01 / 10-12 / 10$ & $0.0189^{* * * *}[0.0044]$ & $1.6892^{* * * *}[0.1471]$ & 0.5961 \\
\hline Chile & $01 / 95-12 / 10$ & $0.0051[0.0046]$ & $0.8571^{* * * *}[0.0931]$ & 0.3436 & $01 / 10-12 / 10$ & $0.0133^{* * * *}[0.0035]$ & $0.8319^{* * * * *}[0.0921]$ & 0.4217 \\
\hline China & $01 / 95-12 / 10$ & $0.0043[0.0071]$ & $1.1229^{* * * *}[0.1321]$ & 0.2404 & $01 / 10-12 / 10$ & $0.0117^{* * *}[0.0046]$ & $1.1801^{* * * * *}[0.1494]$ & 0.4593 \\
\hline Czech.Rep & $01 / 95-12 / 10$ & $0.0072[0.0063]$ & $0.9942^{* * * * *}[0.1975]$ & 0.2799 & $01 / 10-12 / 10$ & $0.0189^{* * *}[0.0058]$ & $1.113^{* * * *}[0.1819]$ & 0.4126 \\
\hline Egypt & $01 / 95-12 / 10$ & $0.0084[0.0101]$ & $0.8219^{* * * *}[0.2193]$ & 0.1706 & $01 / 10-12 / 10$ & $0.015[0.0113]$ & $0.9396^{* * * *}[0.235]$ & 0.2059 \\
\hline Hungary & $01 / 95-12 / 10$ & $0.0070[0.006]$ & $1.573^{* * * * *}[0.1982]$ & 0.4207 & $01 / 10-12 / 10$ & $0.0108 *[0.0064]$ & $1.5675^{* * * * *}[0.2314]$ & 0.5288 \\
\hline India & $01 / 95-12 / 10$ & $0.0050[0.0055]$ & $1.0344^{* * * * *}[0.191]$ & 0.2819 & $01 / 10-12 / 10$ & $0.0129 * *[0.0043]$ & $1.2483^{* * * *}[0.1791]$ & 0.4597 \\
\hline Indonesia & $01 / 95-12 / 10$ & $0.0058[0.0112]$ & $1.4854^{* * * * *}[0.2489]$ & 0.2392 & $01 / 10-12 / 10$ & $0.0159 * * 0.0076]$ & $1.284^{* * * * *}[0.2744]$ & 0.3170 \\
\hline Malaysia & $01 / 95-12 / 10$ & $0.0011[0.008]$ & $0.895^{* * * * *}[0.17]$ & 0.1860 & $01 / 10-12 / 10$ & $0.0088^{* * *}[0.0045]$ & $0.6447^{* * * *}[0.0826]$ & 0.2913 \\
\hline Mexico & $01 / 95-12 / 10$ & $0.0060[0.0043]$ & $1.3277^{* * * * *}[0.086]$ & 0.4961 & $01 / 10-12 / 10$ & $0.0117^{* * * *}[0.0027]$ & $1.2369^{* * * * *}[0.0891]$ & 0.6626 \\
\hline Morocco & $01 / 95-12 / 10$ & $0.0089 *[0.0052]$ & $0.2861^{* * * *}[0.1301]$ & 0.0566 & $01 / 10-12 / 10$ & $0.0097^{* *}[0.0055]$ & $0.4499^{* * * *}[0.1159]$ & 0.1329 \\
\hline Phillipines & $01 / 95-12 / 10$ & $-0.0027[0.007]$ & $0.9807^{* * * *}[0.1835]$ & 0.2420 & $01 / 10-12 / 10$ & $0.007[0.0057]$ & $0.7863^{* * * *}[0.1075]$ & 0.2475 \\
\hline Poland & $01 / 95-12 / 10$ & $0.0048[0.0043]$ & $1.4704^{* * * *}[0.148]$ & 0.3929 & $01 / 10-12 / 10$ & $0.0105^{* * *}[0.0033]$ & $1.4857^{* * * * *}[0.1432]$ & 0.5224 \\
\hline Russia & $01 / 95-12 / 10$ & $0.0145[0.0114]$ & $1.8235^{* * * * *}[0.2784]$ & 0.3249 & $01 / 10-12 / 10$ & $0.0185^{* *}[0.0074]$ & $1.4753^{* * * * *}[0.1821]$ & 0.4127 \\
\hline South Africa & $01 / 95-12 / 10$ & $0.0053[0.0049]$ & $1.1943^{* * * *}[0.1312]$ & 0.4403 & $01 / 10-12 / 10$ & $0.0142^{* * * *}[0.0035]$ & $1.1652^{* * * *}[0.1346]$ & 0.5173 \\
\hline South Korea & $01 / 95-12 / 10$ & $0.0035[0.009]$ & $1.5806^{* * * * *}[0.1343]$ & 0.3319 & $01 / 10-12 / 10$ & $0.0109^{*}\left[0.0066^{]}\right.$ & $1.5261^{* * * *}[0.0882]$ & 0.5587 \\
\hline Turkey & $01 / 95-12 / 10$ & $0.0139 *[0.0069]$ & $1.8793^{* * * * *}[0.2378]$ & 0.2929 & $01 / 10-12 / 10$ & $0.0133 *[0.0063]$ & $1.9882^{* * * * *[0.2784]}$ & 0.4352 \\
\hline Africa & $01 / 95-12 / 10$ & $0.0028[0.0049]$ & $0.8183^{* * * * *}[0.106]$ & 0.3336 & $01 / 10-12 / 10$ & $0.0119^{* * * *}[0.0036]$ & $0.8924^{* * * * *}[0.1166]$ & 0.4916 \\
\hline Asia & $01 / 95-12 / 10$ & $-0.0003[0.0068]$ & $1.1533^{* * * *}[0.106]$ & 0.4688 & $01 / 10-12 / 10$ & $0.0093^{* *}[0.0038]$ & $1.0875^{* * * *}[0.1072]$ & 0.6331 \\
\hline Eastern Eu & $01 / 95-12 / 10$ & $0.0048[0.0046]$ & $1.5536^{* * * *}[0.115]$ & 0.5140 & $01 / 10-12 / 10$ & $0.0098^{* * *}[0.004]$ & $1.5584^{* * * * *}[0.1209]$ & 0.6572 \\
\hline Latin America & $01 / 95-12 / 10$ & $0.0054[0.0042]$ & $1.2716^{* * * *}[0.0746]$ & 0.5486 & $01 / 10-12 / 10$ & $0.0127^{* * * *}[0.003]$ & $1.2448^{* * * *}[0.0739]$ & 0.6321 \\
\hline Emerging & $01 / 95-12 / 10$ & $0.0027[0.004]$ & $1.2769^{* * * *}[0.0759]$ & 0.6365 & $01 / 10-12 / 10$ & $0.0102^{* * * *}[0.0024]$ & $1.2567^{* * * *}[0.0803]$ & 0.7344 \\
\hline
\end{tabular}

Standard errors (in square brackets) have been computed using the procedure described in Newey and West (1994).

* Significantly different from zero at the $10 \%$ levels, respectively.

** Significantly different from zero at the $5 \%$ levels, respectively.

*** Significantly different from zero at the $1 \%$ levels, respectively.

To solve this first issues, we first focus on the fact that local information variables might play a key role in predicting emerging market returns. To do that, a naive transformation of the standard one-factor model is adopted. We believe that the existence of big emerging ERP might be generated by the inclusion of illiquid firms in emerging markets' portfolios.

To eliminate the effect of illiquid stocks we estimate the one-factor model adopting a set of specific liquid emerging stock indices. In practice, we use as dependent variable the excess return computed from the S\&P IFCI. ${ }^{17}$ Similar to the MSCI method for calculating country equity indices, the IFCI uses a subset of the stocks trading in the emerging market. Stocks are selected for inclusion in the index based on size, liquidity and industry. Furthermore share counts used in index calculations are reduced to reflect any limits or restrictions on investments by foreign investors or entities. Using S\&P IFCI stock indices we create our "liquid" macro-area portfolios (i.e. Africa, Asia, Eastern Europe, Latin America and Emerging).

In the first two columns of Table A.2 the 12-months moving averages of the IFCI-MSCI excess return spreads are illustrated. The time varying nature of stock markets returns is still confirmed. Fig. A7 captures the co-movement between the spread and the global stock market. We simply observe that in periods of expansion the spread tend to increase and vice-versa.

The inclusion of this "investable" emerging markets' stock index provides different estimation results. For the common sample Jan 95-Dec 10 we find that all alphas are statistically equal to zero. ${ }^{18}$ In other words, the validity of the one factor model is preserved (Table 4.1).

Once illiquid asset are considered, international investors desire to be compensated (see Table 3.2). A different story can be drawn from the analysis of the sample Jan 00-Dec 10. We find that the "liquid" one-factor model does not hold (i.e. zero alphas are found to be statistically significant only in few stock markets). ${ }^{19}$ Estimation results suggest that local liquidity is puzzling rather than predicting emerging average excess returns (Table 4.2).

In Table A. 2 we report the difference between the MSCI and the IFCI one-factor model estimated alphas. Conform expectations; such differences are mostly negative, meaning that these young markets are use to pay an extra premium. In Table 4.2 we report the Gibbons et al. (1989) joint test on the significance of the alphas. The test are based on 14 and 17

\footnotetext{
17 The S\&P Global BMI is a comprehensive, rules-based index designed to measure global stock market performance. The index covers all publicly listed equities with float-adjusted market values of US\$ 100 million or more and annual dollar value traded of at least US\$ 50 million in all included countries. The S\&P Global BMI is made up of the S\&P Developed BMI and the S\&P Emerging BMI indices. The S\&P IFCI, Standard \& Poors leading investable, emerging market index, is a liquid and investable subset of the S\&P Emerging BMI index. The S\&P Global BMI index covers all publicly listed equities available to institutional investors with float-adjusted market values of US\$100 million or more. At the annual reconstitution, index constituents are removed if their float adjusted market capitalization falls below US\$ 75 million. The S\&P/IFCI index requires that, at the annual reconstitution, a stock must have float-adjusted market capitalization of US\$200 million. During the annual reconstitution, index constituents that fall below US\$200 million, but remain above US\$150 million, remain in the index. The S\&P Global BMI and S\&P IFCI are designed to include the most liquid and investable stocks in developed and emerging markets.Source: Standard \& Poor's.

18 Statistically different from zero alphas (at 10\% confidence level) are found in the following three markets: Brazil, Morocco and Turkey.

19 Model's validity is preserved only in the following countries: Argentina, Egypt and Philippines.
} 
Table 4.2

S\&P IFCI Gibbons, Ross and Shanken (1989) multivariate test ( $p$-values are reported in parentheses).

\begin{tabular}{lllll}
\hline Portfolio (IFCI) & Jan 95-Dec 10 & & Jan 00-Dec 10 & Chi-Test \\
\cline { 2 - 3 } & Chi-Test & F-Test & F-Test & $32.2018(0.0142)$ \\
\hline Emerging & $7.3005(0.9225)$ & $0.4807(0.9412)$ & $1.6359(0.0663)$ \\
\hline
\end{tabular}

emerging markets. ${ }^{20}$ We stress that our results are strictly time dependent. As in Section 3, the liquid CAPM holds only if the sample Jan 95-Dec 10 is considered. Once the analysis is restricted to the sample Jan 00-Dec 10 the null hypothesis of having all alphas jointly equal to zero is rejected. We argue that local liquidity does not solve our empirical puzzle.

Liquidity can be intended as the ability to engage in rapidly trading a large number of securities at a low cost with little impact on market prices. Liquidity is a key issue in international asset pricing. Using a simple two-factor model we next try to study the role of local liquidity factors on excess returns predictability. We find that the alternative approach does not provide any benefits to empirically solve of the puzzle.

\subsection{The local impact of liquidity measures}

Zhang (2010) claims that liquidity measures require the use of high-frequency data. Emerging markets' high-frequency data are often not available. To overcome this problem researchers and practitioners tend to propose low-frequency liquidity proxies. For example, bid-ask spread, market depth, trading volume, price impact per dollar traded and other sophisticated proxies have been employed to study the effects o liquidity on stock prices. Most studies focus on one particular dimension of liquidity.

The first class of liquidity proxies is mainly based on the trading activity. Roll (1984) develops an implicit measure of the effective bid-ask spread on the basis of the serial covariance of daily price changes. Lesmond et al. (1999) argue that stocks with lower liquidity and higher transaction costs are more likely to have either zero volume and zero return days or positive volume and zero return days, so they propose the use of the proportion of zero return days as a proxy for liquidity. Liu (2006) proposes a liquidity measure, which is a standardized turnover-adjusted number of zero daily trading volumes over the prior $x$ months.

The second class focuses on the price impact of trades. Amihud and Mendelson (1986) focus on bid-ask spreads related to trading costs. They find that, if a security is less liquid and hence it is most costly to trade, then that security should provide a higher return as compensation. Focusing on the trading quantity, Datar et al. (1998) support the predictions of the Amihud and Mendelson's model. Amihud (2002) develops a price impact measure based on the daily price response associated with one dollar of trading volume. His illiquidity measure is the average across stocks of the daily ratio of absolute stock return to dollar volume. He finds that expected market illiquidity positively affects ex-ante stock excess return.

Pastor and Stambaugh (2003) focus on the price impact dimension of liquidity. In assessing the role of liquidity on the US stock market they create a measure that essentially tries to associate lower liquidity with stronger lower volume related return reversals. They create "liquidity betas" and find that stocks with higher betas (i.e. higher sensitivity to aggregate liquidity shocks), offer higher expected returns.

Chordia et al. (2000) proxy liquidity by trading volume and turnover, measured at the firm level. They find that stock with more volatile liquidity have lower expected returns. Bekaert et al. (2007) examine a measure of liquidity that captures the proportion of zero daily firm returns averaged over a month, in the context of emerging markets. They find that this liquidity measure significantly predicts future returns, whereas alternative measures such as turnover do not. Using data on 27 emerging markets for the period Jan 92-Dec 99, Jun et al. (2003) find that stock returns in emerging countries are positively correlated with aggregate market liquidity as measured by turnover ratio, trading value and turnover-volatility multiple.

The financial literature indicates that the concept of liquidity is a complex one. As discussed above, there are many possible ways to construct or retrieve liquidity measures. It is standard practice to use as liquidity proxies those measures related to trading volume. A common feature of stock is that if trading volume is low, then an investor may require an expected return premium for holding a stock that does not trade very frequently. To measure the price impact, a regression approach is often used, where the return is regressed on trading volume or other liquidity proxies.

In this paper, we study the impact of liquidity on 19 different emerging stock markets and 5 equally weighted portfolios. We use a two-factor linear model, where the second factor is the turnover by volume (i.e. our proxy to measure liquidity).

This measure shows the aggregation of the number of shares_expressed in thousands-for each stock in the index traded on a particular day. Volume, market capitalization, turnover by volume and other important variables to measure

\footnotetext{
${ }^{20}$ We perform the test by neglecting Argentina, Colombia, Egypt, Morocco and Russia (in the sample Jan 95-Dec 00) and Argentina and Colombia (in the sample Jan 00-Dec 00).
} 

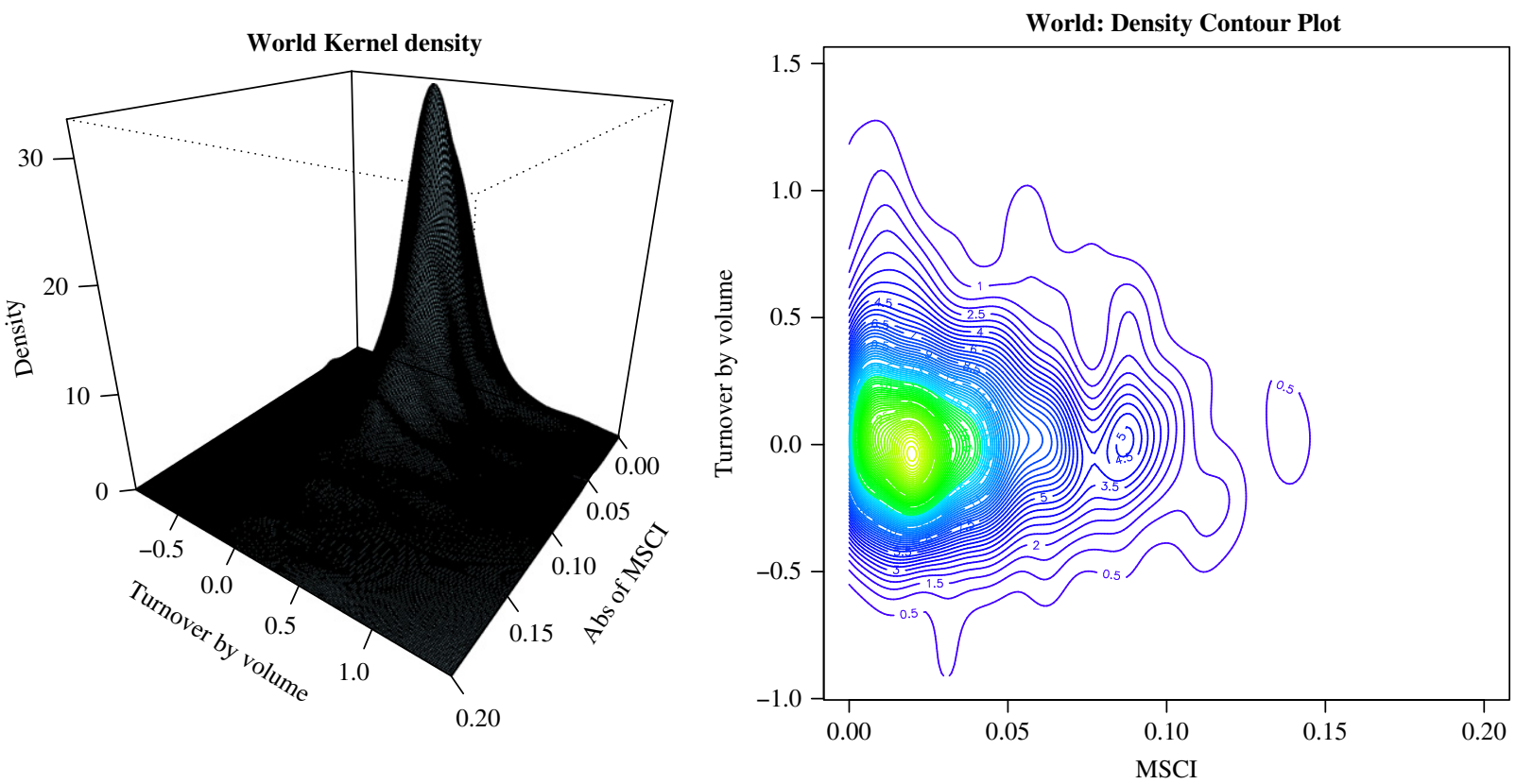

Fig. 4.1. World: Kernel density and density contour plot (sample: Feb 73-Dec 10).

market liquidity are not available for our emerging MSCI TRIs. Turnover by volume series are available for the Chinese (i.e. Shanghai Composite Index) and Indian (i.e. S\&P 500 CNX) stock markets.

To solve this problem we use the Datastream Global Equity Indices (DGEIs) dataset. ${ }^{21}$ Stocks are classified by industry and sector type (e.g. banks, life assurance and real estate are sectors included in the financial industry). The classification structure is based on the Industry Classification Benchmark (ICB) jointly created by FTSE and Dow Jones and is updated when changes are made to this classification. Each sector contains a representative sample of major stocks within that classification. Datastream uses these constituent stocks when calculating an index for a sector. DGEIs break down into six sector levels for each country. Level 1 is the market index, this covers all the sectors in each region or country. Level 2 divides the market into 10 industries and covers all the sectors within each group in each region or country. Where possible, the market index is used, and where not - according to level 2 - the sum of the existing industry indices become a valid substitute. Our local liquidity two-factor model is estimated via Eq. (4.1)

$$
R_{i, t}-R_{f, t}=\alpha_{i}+\beta_{i, m}\left(R_{m, t}-R_{f, t}\right)+\gamma_{i} T b V_{t-1}+\varepsilon_{i, t}
$$

where $T b V_{t-1}$ represents the one-period lagged turnover-by-volume and $R_{m, t}-R_{f, t}$ is the usual market factor. This standard two-factor model implies that the expected excess return of a stock is explained by the covariance of its returns with the market and the liquidity (i.e. turnover-by-volume). The intercept can be interpreted as the risk-adjusted return of asset $i$ relative to the two-factor model. If the two-factor model explains asset returns, the intercepts should be statistically equal to zero. ${ }^{22}$

In contrast to Liu (2006), we find that our measure of liquidity does not capture market liquidity conditions. Table A.3 displays the estimation results of Eq. (4.1). We find that the liquidity coefficient $\gamma_{i}$ is rarely statistically different from zero (i.e. turnover-by-volume does not predict excess returns). Intuitively, one would expect that, as soon as liquidity increases, counterparts for transactions are easy to find. As a consequence the overall risk should be lower (i.e. no extra ERP). Estimation results show that our liquidity proxy, does not play a key role in predicting emerging stock prices. The use of the turnover by volume as local risk factor might be questioned.

Figs. 4.1-4.4 support our estimation results. These figures illustrate the kernel densities and their related contour plots in the "excess returns' absolute changes_liquidity changes (i.e. turnover by volume) space" for the following macro stock portfolios: World, Asia, Latin America and Emerging.

21 Datastream Global Equity Indices draw on the wealth of the Thomson Datastream database to provide a range of equity indices across 53 countries, 32 regions and 170 sectors worldwide. They form a comprehensive, independent standard for equity research and benchmarking. For each market, a representative sample of stocks covering a minimum 75-80\% of total market capitalization enables market indices to be calculated. By aggregating market indices for regional groupings, regional and world indices are produced. Within each market, stocks are allocated to industrial sectors using the Industry Classification Benchmark (ICB) jointly created by FTSE and Dow Jones. Sector indices are then calculated. Source: Thomson Reuters.

22 Note that the inclusion of a lagged volume factor in a multifactor return pricing model may underestimate the fact that future may not turn out to be like the past. 

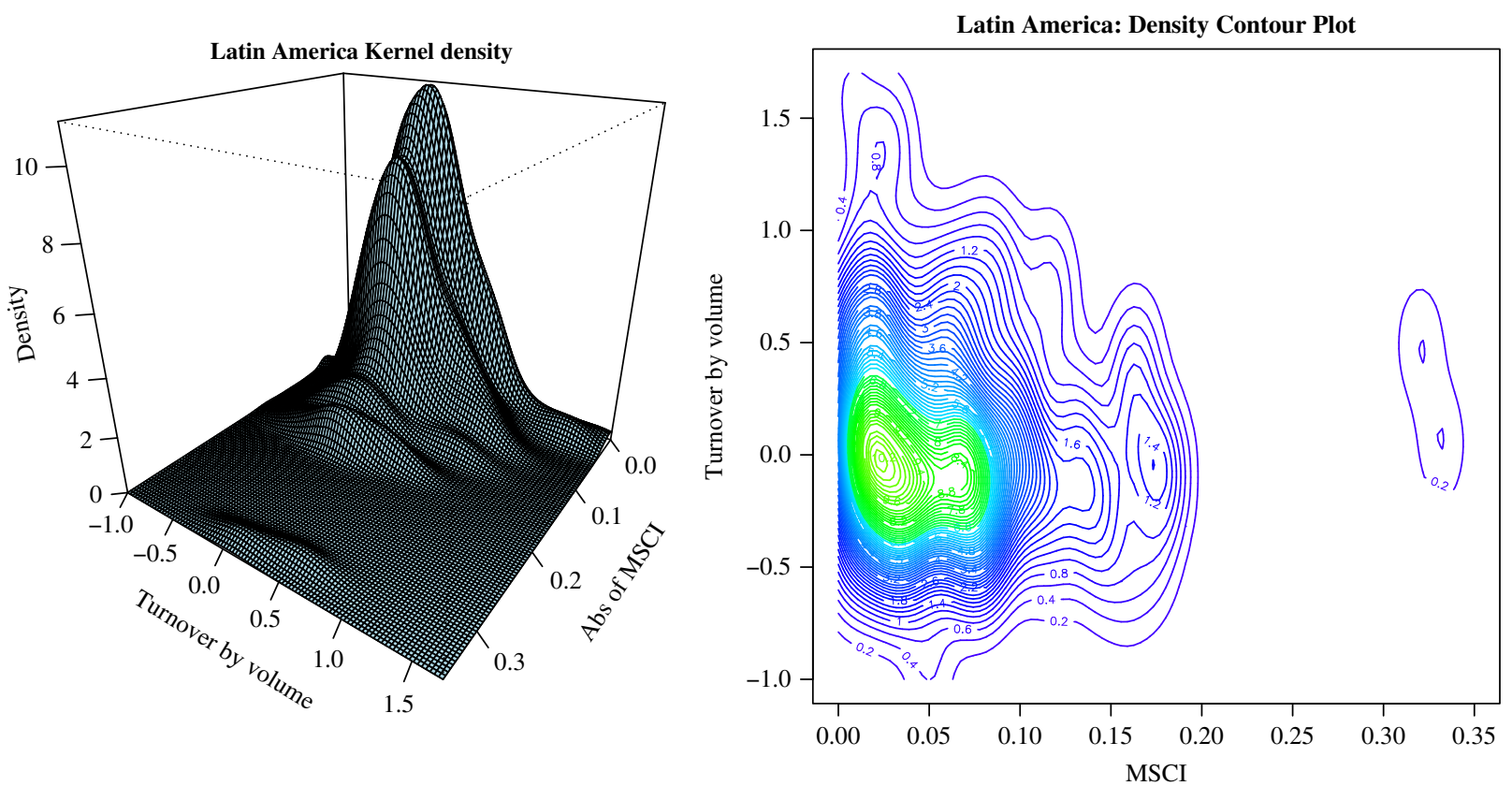

Fig. 4.2. Latin America: Kernel density and density contour plot (sample: Sep 94-Dec 10).
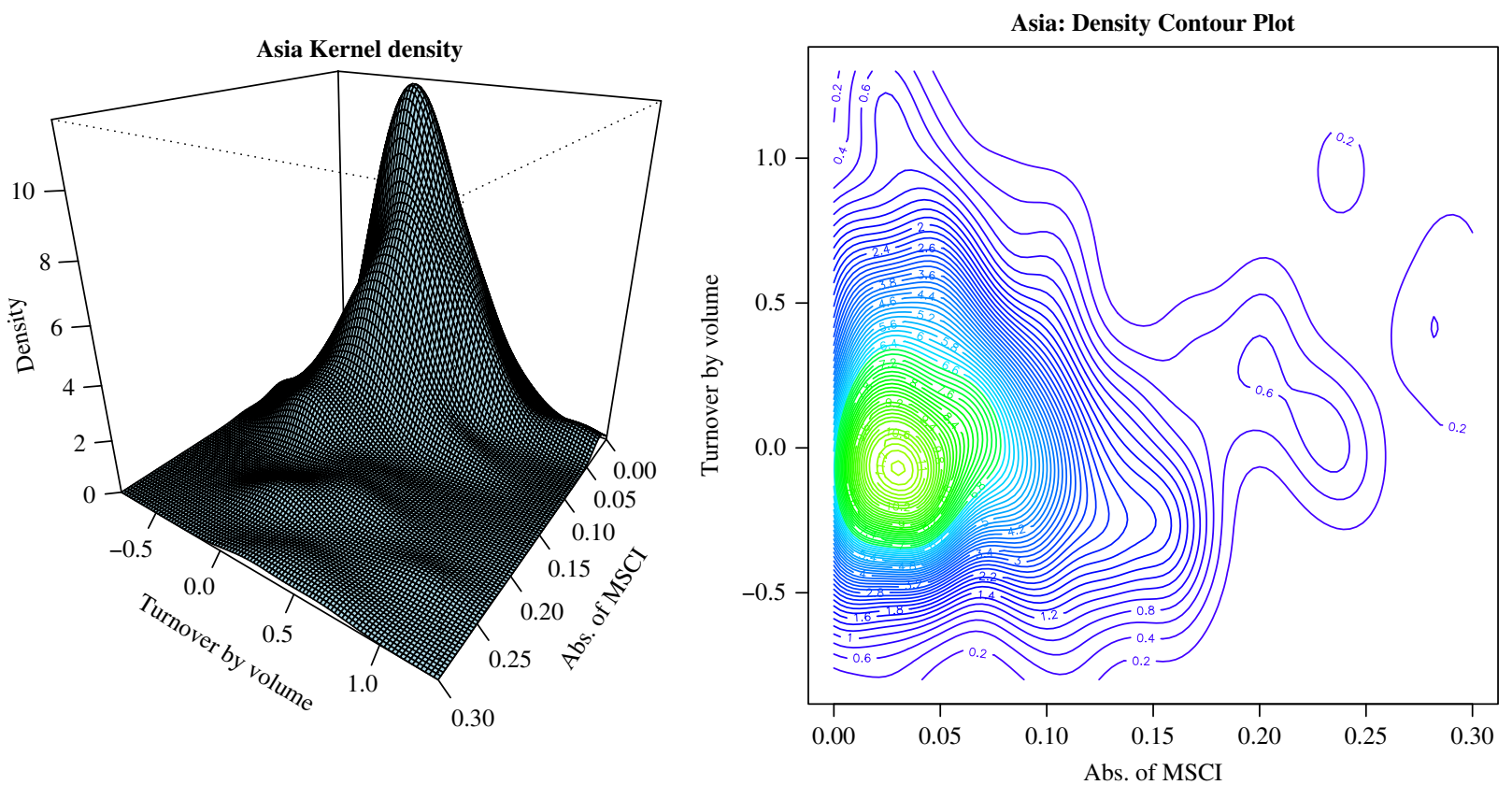

Fig. 4.3. Asia: Kernel density and density contour plot (sample: Jan 90-Dec 10).

Intuitively, we expect that to an absolute change in the excess returns (horizontal axis) corresponds a change in the total number of transaction (vertical axis). Therefore, it is reasonable to assume that investors are willing to change their portfolio allocation when the excess returns are subject to variations. If illiquidity takes place a higher concentration towards the lower-corner should be detected. Graphically, a L-shape justifies stock markets illiquidity.

Our figures support only partially the presence of an illiquid environment. Features of illiquidity seem to be present only in the Latin America portfolio. We conclude that local liquidity factors are not able to explain the alpha puzzle. ${ }^{23}$ In Section 5 a simple partial equilibrium model solves the "alpha puzzle".

\footnotetext{
${ }^{23}$ A similar result is found in Harvey (2004).
} 

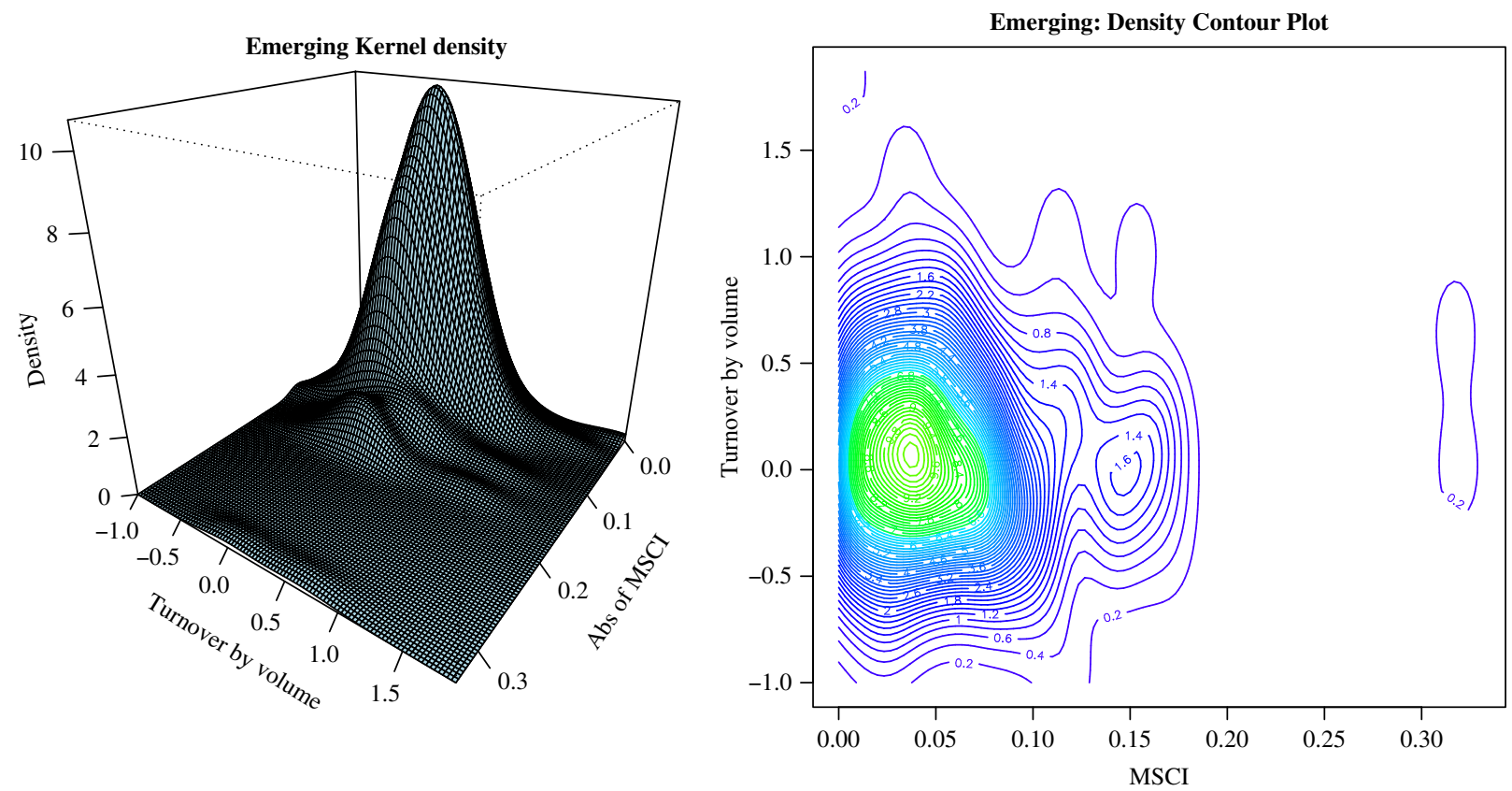

Fig. 4.4. Emerging: Kernel density and density contour plot (sample: Mar 95-Dec 10).

\section{Transaction costs and model's validity: A two-country model}

Several works on foreign equity investment restrictions, and in general, on international asset pricing, show that barriers may influence asset prices. ${ }^{24}$ Domowitz et al. (1997a,b) support the general consensus that the simplest explanation for the existence of stock price premia is the liquidity hypothesis. In their model, the price premium for not imposing restrictions on shares reflects the lower transaction costs and the greater liquidity in these shares if compared with a less traded shares. Theoretical literature predicts that higher transaction costs lead to higher risk-adjusted expected returns (i.e. investors seeking to maximize their final net payoffs demand compensation for investing in securities with high transaction costs).

In a seminal contribution, Aiyagari (1993) shows that transaction costs are responsible for the spread between the returns to stocks and bonds. He argues that in absence transactions costs, the return on stocks must be equal to the risk-free rate since stocks are also risk-free. In a simple model Stulz (1981) shows that foreign investment for a domestic investor is costly. On this issue, Amihud and Mendelson $(1986,1990)$ find that expected returns are highly sensitive to changes in transaction costs.

It is commonly believed that trading costs have an important effect on emerging market investment strategies. Harvey (1994) argues that in presence of high trading costs an investor can only implement a buy-and-hold strategy. Domowitz et al. (2001) point out that execution costs, especially in illiquid markets, can dramatically reduce the notional return to an investment strategy. Using panel data for 42-countries, they find that emerging markets have significantly higher trading costs.

The two-country/two-investor partial equilibrium model proves that the quadratic cost generates higher excess returns. In other words, investors need to be compensated for suffering such costs. We argue that this extra premium justifies the presence of positive and statistically significant alphas. In our model, additional costs do not necessarily correspond to standard transaction costs. We assume that an international investor who invests in emerging stock markets is simply subject to more difficulties.

In this one-period model each country issues a single stock that is traded in the international capital market. The economy is populated by two representative investors. Each of them maximizes his/her expected utility.

Assumption 1. Investors have CRRA preferences

$$
E\left[u_{1}\left(c_{1}\right)\right]=-E\left[\exp \left(-\alpha_{1} c_{1}\right)\right], \quad l=\{d, e\}
$$

\footnotetext{
${ }^{24}$ See Stulz (1981), Eun and Janakiramanan (1986) and Hietala (1989), among others.
} 
Without loss of generality we assume that $\alpha_{1}=\alpha_{2}=1$ and also that the initial endowment of each consumer is $W_{d}^{0}=W_{e}^{0}=1$. Stock prices are normalized to be 1 . In addition each stock offers a return $r^{j}$ where $j=\{d, e\}$. Stock returns are jointly normally distributed. The vector of returns and the variance covariance matrix:

$$
\boldsymbol{r}=\left[\begin{array}{l}
r^{d} \\
r^{e}
\end{array}\right] \sim N(\boldsymbol{e}, \boldsymbol{V}) \quad \boldsymbol{e}=\left[\begin{array}{c}
e^{d} \\
e^{e}
\end{array}\right], \quad \boldsymbol{V}=\left[\begin{array}{cc}
\sigma_{d}^{2} & \sigma_{d e} \\
\sigma_{d e} & \sigma_{e}^{2}
\end{array}\right]
$$

We allow for the existence of a riskless asset that pays a fixed return equal to $r^{f}$. Each investor lives in his/her domestic country and can invest his/her wealth in these 3 assets. Being a one period model, the gross return of this investment (i.e. one-period liquidation value of the portfolio) is entirely consumed in the next period.

Formally:

$$
c_{l}=\left(1+\omega_{l}^{\prime} \boldsymbol{r}+\left(1-\omega_{l}^{\prime} 1\right) r^{f}\right) \quad \omega_{\boldsymbol{l}}=\left[\begin{array}{c}
\omega_{l}^{d} \\
\omega_{l}^{e}
\end{array}\right]
$$

Given the CARA utility function and the normality assumption, we can maximize the certainty equivalence problem (5.2) subject to (5.3) and (5.4):

$$
E\left[c_{l}\right]-\frac{1}{2} \alpha_{l} \operatorname{Var}\left[c_{l}\right]
$$

where

$$
\begin{aligned}
& E\left[c_{l}\right]=\left(1+\omega_{\boldsymbol{l}}^{\prime} \boldsymbol{e}+\left(1-\omega_{\boldsymbol{l}}^{\prime} 1\right) r^{f}\right) \\
& \operatorname{Var}\left[c_{l}\right]=\omega_{\boldsymbol{l}}^{\prime} \boldsymbol{V} \omega_{\boldsymbol{l}}
\end{aligned}
$$

Assumption 2. The domestic investor " $d$ " faces quadratic transaction costs for investing in the stock issued by the emerging country.

The domestic investor $d$ chooses $\omega_{\boldsymbol{d}}$ to maximize total wealth:

$$
\max _{\omega_{d}}\left(1+\omega_{d}^{\prime} \boldsymbol{e}+\left(1-\omega_{d}^{\prime} \mathbf{1}-\frac{1}{2} \omega_{d}^{\prime} B \omega_{d}\right) r^{f}\right)-\frac{1}{2} \omega_{d}^{\prime} V \omega_{d}
$$

where

$$
\boldsymbol{B}=\left[\begin{array}{ll}
0 & 0 \\
0 & \beta
\end{array}\right]
$$

Taking the first order condition for problem (5.5) and rearranging, we get the vector of optimal weights of the domestic investor

$$
\boldsymbol{\omega}_{\boldsymbol{d}}=\left(\boldsymbol{V}+r^{f} \boldsymbol{B}\right)^{-1}\left(\boldsymbol{e}-\mathbf{1} r^{f}\right)
$$

Similarly, the optimal vector of weights for investor $e$ is

$$
\omega_{\boldsymbol{e}}=\boldsymbol{V}^{-1}\left(\boldsymbol{e}-\mathbf{1} r^{f}\right)
$$

Assumption 3. The total wealth invested in each stock is equal to one.

Equilibrium in the capital markets requires

$$
\omega_{d}+\omega_{e}=1
$$

Plugging (5.6) and (5.7) into (5.8), the equilibrium excess return vector is

$$
\left(\boldsymbol{V}+r^{f} \boldsymbol{B}\right)^{-1}\left(\boldsymbol{e}-\mathbf{1} r^{f}\right)+\boldsymbol{V}^{-1}\left(\boldsymbol{e}-\mathbf{1} r^{f}\right)=1\left(\boldsymbol{e}-\mathbf{1} r^{f}\right)=\left[\left(\boldsymbol{V}+r^{f} \boldsymbol{B}\right)^{-1}+\boldsymbol{V}^{-1}\right]^{-1} \mathbf{1}
$$

In absence of transaction costs the equilibrium vector of excess returns is

$$
\left(\hat{\boldsymbol{e}}-1 r^{f}\right)=\left[\boldsymbol{V}^{-1}+\boldsymbol{V}^{-1}\right]^{-1} \mathbf{1}=\frac{1}{2} \boldsymbol{V} \mathbf{1}
$$




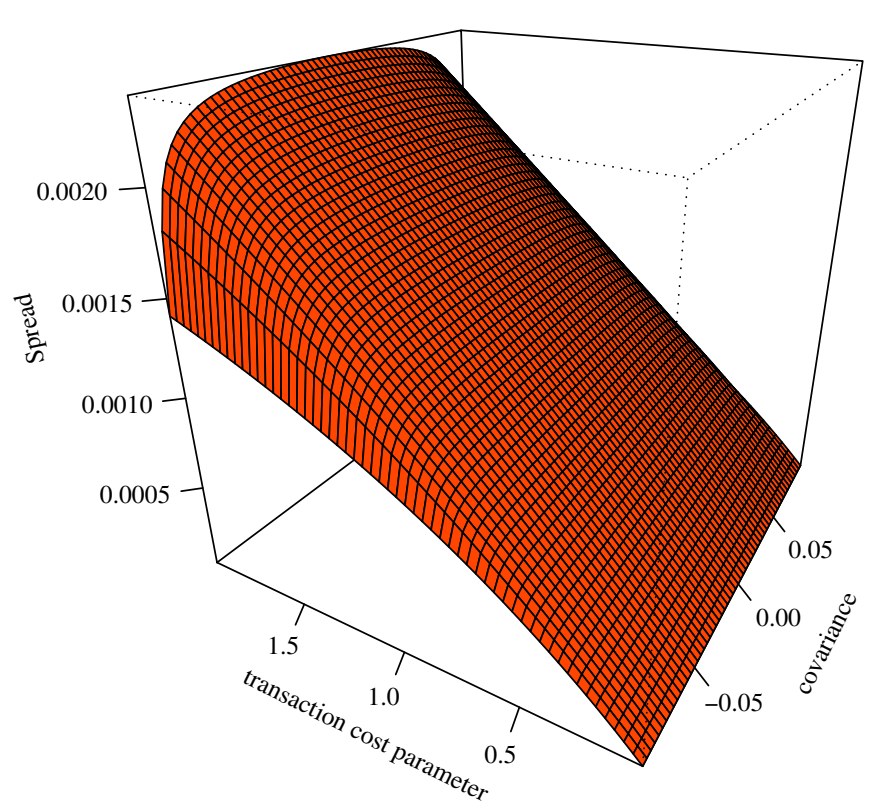

Fig. 5.1. Calibration: emerging stock market premia in presence of transaction costs.

Proposition 1 proves that the inclusion of quadratic costs generates an extra premium for the domestic investors who want to invest in the emerging market.

Proposition 1. If and only if

$$
\left[\left[\left(\boldsymbol{V}+r^{f} \boldsymbol{B}\right)^{-1}+\boldsymbol{V}^{-1}\right]^{-1}-\frac{1}{2} \boldsymbol{V}\right] \mathbf{1}>0 .
$$

emerging markets delivers higher average excess returns than developed markets.

The proof is given is the Appendix B. In Fig. 5.1 the we calibrate our model's result for specific values of the transaction cost parameter and for some values of the covariance between the emerging and developed stocks. It is evident how to an increase in the transaction cost parameter $\beta$ corresponds to a higher premium. Note that such extra premium is decreasing in the absolute value of the covariance between the two stocks.

Our model solves the "alpha puzzle". This result relies on the assumption that the domestic investor is subject to additional quadratic costs. Nevertheless, the model does not give a precise classification of these extra costs. We argue that trading and/or information could also play a key role. Ahearne et al. (2004) show that barriers to foreign investors have no economic role, indeed asymmetric information and poor quality of information may induce investors to prefer domestic assets and require a premium for investing in emerging countries.

\section{Liquidity as global risk factor: Understanding the beta puzzle}

In fully integrated markets, local liquidity measures or other local risk factors are strongly influenced by global risk factors. Thus, an increase in liquidity can be associated to an increase in cross-country correlation and this leads to an increase in the exposure to global risk. We show that emerging excess returns display a strong time varying component and they seem to be more affected by global risk factor rather than local ones.

It is largely accepted that liquidity shocks generate price changes. The link between returns and liquidity has been widely discussed. A consistent number of these studies assert that liquidity is priced. ${ }^{25} \mathrm{~A}$ large part of these empirical studies focuses on the U.S. market. They claim that in order to be priced at aggregate level, there must be a systemic component to liquidity variation, and overall, stocks must perform badly when liquidity dries up (i.e. excess returns are negatively related to liquidity). Pastor and Stambaugh (2003) suggest that it would be useful to explore whether some form of systemic liquidity risk is priced in other financial markets, such as international or emerging equity markets.

\footnotetext{
${ }^{25}$ See, for example Amihud (2002), Jones (2002) and Pastor and Stambaugh (2003).
} 
Table 6.1

Conditional CAPM Estimation Results (VIX).

\begin{tabular}{|c|c|c|c|c|c|c|c|c|c|c|}
\hline MSCI TRI & Period & $\alpha$ & $\beta$ & $\psi$ & $R^{2}$ & Period & $\alpha$ & $\beta$ & $\psi$ & $R^{2}$ \\
\hline Australia & $01 / 95-12 / 10$ & $0.0050[0.0032]$ & $1.0604^{* * * *}[0.0858]$ & $0.316^{* *}[0.1315]$ & 0.6749 & $01 / 10-12 / 10$ & $0.0111^{\text {***:k }}[0.0026]$ & $1.1205^{* * * *}[0.0947]$ & $0.3669^{* *}[0.1791]$ & 0.7435 \\
\hline Canada & $01 / 95-12 / 10$ & $0.0061^{* * k}[0.0026]$ & $1.1205^{* * * *[0.0716]}$ & $0.2898 * *[0.1159]$ & 0.7199 & $01 / 10-12 / 10$ & $0.0087^{* * * *}[0.0025]$ & $1.1228^{* * *}[0.0872]$ & $0.2607^{* *}[0.1214]$ & 0.7381 \\
\hline France & $01 / 95-12 / 10$ & $0.0011[0.0016]$ & $1.1807^{* * * *}[0.0533]$ & $-0.0837[0.0853]$ & 0.7884 & $01 / 10-12 / 10$ & $0.0013[0.0016]$ & $1.236^{* * * *}[0.0482]$ & $-0.1059 *[0.0597]$ & 0.8485 \\
\hline Germany & $01 / 95-12 / 10$ & $0.0007[0.002]$ & $1.3145 * * * 0.0941]$ & $-0.1315[0.1206]$ & 0.7530 & $01 / 10-12 / 10$ & $0.0021[0.002]$ & $1.4079^{* * *[0.0983]}$ & $-0.1858[0.12]$ & 0.8182 \\
\hline Italy & $01 / 95-12 / 10$ & $-0.0001[0.003]$ & $1.1443^{* * * *}[0.0875]$ & $-0.1007[0.1382]$ & 0.5704 & $01 / 10-12 / 10$ & $0.0002[0.0029]$ & $1.1926^{* * * *}[0.0947]$ & $-0.1142[0.1282]$ & 0.7137 \\
\hline Japan & $01 / 95-12 / 10$ & $-0.0051[0.0036]$ & $0.8303^{* * * *}[0.0781]$ & $-0.0511[0.0879]$ & 0.4545 & $01 / 10-12 / 10$ & -0.00250 .0030 & $0.7514^{* * * *}[0.0794]$ & $0.0089[0.0748]$ & 0.4899 \\
\hline Netherlands & $01 / 95-12 / 10$ & $0.0012[0.0019]$ & $1.1767^{* * * *}[0.0693]$ & $0.0714[0.094]$ & 0.7737 & $01 / 10-12 / 10$ & $0.0019[0.002]$ & $1.2471^{* * * *}[0.0672]$ & $0.0846[0.07]$ & 0.8263 \\
\hline Norway & $01 / 95-12 / 10$ & $0.0054[0.0036]$ & $1.2679 * * *[0.1206]$ & $0.6588^{* * * *}[0.2265]$ & 0.6082 & $01 / 10-12 / 10$ & $0.0123^{* * * *}[0.0029]$ & $1.4076^{* * *}[0.1188]$ & $0.4688^{* * * * *}[0.1469]$ & 0.7074 \\
\hline Sing & $01 / 95-12 / 10$ & $0.0011[0.0051]$ & $1.1699 * * *[0.1163]$ & $0.2759 *[0.1571]$ & 0.4876 & $01 / 10-12 / 10$ & $0.0068^{* *}[0.003]$ & $1.0664^{* * *}[0.1129]$ & $0.4438^{* * * * *}[0.146]$ & 0.5905 \\
\hline Spain & $01 / 95-12 / 10$ & $0.0052 *[0.0028]$ & $1.2155^{* * * *}[0.0796]$ & $0.1307[0.121]$ & 0.6485 & $01 / 10-12 / 10$ & $0.0049[0.0032]$ & $1.2531^{* * * *}[0.0759]$ & $0.0468[0.1045]$ & 0.6998 \\
\hline Switz & $01 / 95-12 / 10$ & $0.0032[0.0022]$ & $0.8349 * * * 0.0545]$ & $-0.0702[0.123]$ & 0.5717 & $01 / 10-12 / 10$ & $0.0033^{* *}[0.0015]$ & $0.8555^{* * * *[0.0574]}$ & $-0.1855 *[0.0577]$ & 0.6768 \\
\hline UK & $01 / 95-12 / 10$ & $0.0007[0.0016]$ & $0.9041^{* * * *}[0.0474]$ & $-0.0339[0.0939]$ & 0.7923 & $01 / 10-12 / 10$ & $0.0007[0.0014]$ & $0.9671^{* * * *}[0.0429]$ & $-0.0038[0.046]$ & 0.8491 \\
\hline USA & $01 / 95-12 / 10$ & $0.0015[0.0013]$ & $0.9591 * * * * 0.0287]$ & $0.0122[0.0434]$ & 0.9006 & $01 / 10-12 / 10$ & $-0.0011[0.0008]$ & $0.9469^{* * * *}[0.0294]$ & $-0.0180[0.0329]$ & 0.9375 \\
\hline Argentina & $01 / 95-12 / 10$ & $0.0101[0.0062]$ & $1.0824^{* * * *}[0.1646]$ & $1.0211^{* * * *}[0.2266]$ & 0.2405 & $01 / 10-12 / 10$ & $0.0154 *[0.0081]$ & $1.0234^{* * * *}[0.1875]$ & $1.0048^{* * * *}[0.2405]$ & 0.2170 \\
\hline Brazil & $01 / 95-12 / 10$ & $0.0105[0.0059]$ & $1.6205^{* * * *}[0.1328]$ & $0.4484^{* *}[0.2423]$ & 0.4611 & $01 / 10-12 / 10$ & $0.019^{* * * * *}[0.0046]$ & $1.643^{* * *}[0.1617]$ & $0.3726^{* * *}[0.1737]$ & 0.5828 \\
\hline Chile & $01 / 95-12 / 10$ & $0.0061[0.0048]$ & $0.7981 * * *[0.1103]$ & $0.6467^{* * * * *}[0.1634]$ & 0.3653 & $01 / 10-12 / 10$ & $0.0142^{* * * *[0.004]}$ & $0.7671^{* * *[0.1185]}$ & $0.6158^{* * * * *}[0.1672]$ & 0.4466 \\
\hline China & $01 / 95-12 / 10$ & $0.0004[0.0064]$ & $1.1416^{* * * *}[0.1465]$ & $0.0956[0.1929]$ & 0.2347 & $01 / 10-12 / 10$ & $0.0089 *[0.0049]$ & $1.1766^{* * * *}[0.1636]$ & $0.0206[0.1178]$ & 0.4400 \\
\hline Colombia & $01 / 95-12 / 10$ & $0.0144 *[0.0077]$ & $0.7355^{* * * *}[0.1672]$ & $0.6854^{* * *}[0.2754]$ & 0.1503 & $01 / 10-12 / 10$ & $0.0283^{* * * k}[0.0064]$ & $0.8822^{* * * *}[0.16]$ & $0.7573^{* * * *}[0.2904]$ & 0.2630 \\
\hline Czech Rep. & $01 / 95-12 / 10$ & $0.0104 *[0.006]$ & $0.873^{* * * *}[0.2009]$ & $0.6815^{* * *}[0.2788]$ & 0.2651 & $01 / 10-12 / 10$ & $0.02^{* * * * *}[0.0059]$ & $1.0547^{* * * *}[0.1848]$ & $0.4472^{* * * * *}[0.1522]$ & 0.4025 \\
\hline Egypt & $01 / 95-12 / 10$ & $0.0156[0.0089]$ & $0.7543^{* * * *}[0.2058]$ & $0.7579^{* * \cdots * k}[0.2352]$ & 0.1670 & $01 / 10-12 / 10$ & $0.0171[0.0108]$ & $0.8991^{* * * *[0.2186]}$ & $0.6416^{* * * *}[0.2156]$ & 0.2250 \\
\hline Hungary & $01 / 95-12 / 10$ & $0.0108 *[0.0058]$ & $1.4972 * * *[0.1927]$ & $0.7114^{* * *}[0.3193]$ & 0.4293 & $01 / 10-12 / 10$ & $0.0119 *[0.0061]$ & $1.493^{* * * *}[0.227]$ & $0.5341 *[0.2625]$ & 0.5270 \\
\hline India & $01 / 95-12 / 10$ & $0.0066[0.0054]$ & $1.0164 * * * 0.1903]$ & $0.3127[0.2031]$ & 0.2749 & $01 / 10-12 / 10$ & $0.0143^{\text {****k }}[0.004]$ & $1.2186^{* * * *}[0.1857]$ & $0.3071^{*}[0.1775]$ & 0.4306 \\
\hline Indonesia & $01 / 95-12 / 10$ & $0.0076[0.0118]$ & $1.4479 * * *[0.2862]$ & $0.3683[0.4296]$ & 0.2300 & $01 / 10-12 / 10$ & $0.0194^{* *}[0.0078]$ & $1.1424^{* * * * *}[0.2395]$ & $0.8605^{* * * *}[0.242]$ & 0.3150 \\
\hline Malaysia & $01 / 95-12 / 10$ & $0.0016[0.0087]$ & $0.8318 * * * * 0.1869]$ & $-0.0085[0.2355]$ & 0.1674 & $01 / 10-12 / 10$ & $0.0091 * *[0.0042]$ & $0.546^{* * * *} 0.0823$ & $0.3142^{* * * *}[0.0999]$ & 0.2412 \\
\hline Mexico & $01 / 95-12 / 10$ & $0.0083[0.0038]$ & $1.2609^{* * * *}[0.0823]$ & $0.6323^{* * *}[0.3097]$ & 0.5133 & $01 / 10-12 / 10$ & $0.013^{* * * *}[0.0027]$ & $1.1846^{* * * *}[0.079]$ & $0.4791^{* * * *}[0.1097]$ & 0.6818 \\
\hline Morocco & $01 / 95-12 / 10$ & $0.0087^{*}[0.0049]$ & $0.2473^{* * * *}[0.123]$ & $0.0981[0.1877]$ & 0.0347 & $01 / 10-12 / 10$ & $0.0085[0.0056]$ & $0.4166^{* * * *}[0.1211]$ & $0.0439[0.1585]$ & 0.1007 \\
\hline Phil & $01 / 95-12 / 10$ & $-0.0021[0.0072]$ & $0.9266^{* * * *}[0.1872]$ & $0.463^{* * * *}[0.1793]$ & 0.2294 & $01 / 10-12 / 10$ & $0.0067[0.0059]$ & $0.7214^{* * * *}[0.1125]$ & $0.5642^{* * * * *}[0.1236]$ & 0.2376 \\
\hline Poland & $01 / 95-12 / 10$ & $0.0056[0.004]$ & $1.4669^{* * * *}[0.145]$ & $0.4332[0.3267]$ & 0.3981 & $01 / 10-12 / 10$ & $0.011^{* * * k}[0.0034]$ & $1.4959^{* * * *}[0.1439]$ & $0.2809[0.2262]$ & 0.5188 \\
\hline Russia & $01 / 95-12 / 10$ & $0.018 *[0.0108]$ & $1.7779 * * * * 0.2654]$ & $0.3709[0.3763]$ & 0.2479 & $01 / 10-12 / 10$ & $0.0174^{* *}[0.0068]$ & $1.4572^{* * *}[0.1749]$ & $0.4073^{*}[0.2166]$ & 0.4298 \\
\hline South Africa & $01 / 95-12 / 10$ & $0.0055[0.0044]$ & $1.1678^{* * * *}[0.111]$ & $0.5673[0.401]$ & 0.4801 & $01 / 10-12 / 10$ & $0.0135^{\text {****k }}[0.003]$ & $1.1777^{* * * * *}[0.1209]$ & $0.4428[0.2966]$ & 0.5686 \\
\hline South Korea & $01 / 95-12 / 10$ & $0.0036[0.0089]$ & $1.5418^{* * * *}[0.1323]$ & $-0.1613[0.264]$ & 0.3180 & $01 / 10-12 / 10$ & $0.0114^{*}[0.0065]$ & $1.4727^{* * * *}[0.0802]$ & $0.1267[0.1291]$ & 0.5541 \\
\hline Turkey & $01 / 95-12 / 10$ & $0.0134 *[0.0069]$ & $1.9178 * * *[0.266]$ & $-0.0301[0.3143]$ & 0.2930 & $01 / 10-12 / 10$ & $0.0127^{* * *}[0.006]$ & $2.0092^{* * *}[0.307]$ & $-0.2653[0.2815]$ & 0.4026 \\
\hline Developed & $01 / 95-12 / 10$ & $0.0008[0.0011]$ & $1.0969 * * * 0.0377]$ & $0.0936^{* * *}[0.0417]$ & 0.9193 & $01 / 10-12 / 10$ & $0.0032^{* * * * k}[0.0009]$ & $1.1342^{* * * *}[0.0373]$ & $0.0927^{* * *}[0.0403]$ & 0.9345 \\
\hline Asia & $01 / 95-12 / 10$ & $0.0007[0.0078]$ & $1.1787^{* * * *}[0.1425]$ & $0.2521[0.1746]$ & 0.4334 & $01 / 10-12 / 10$ & 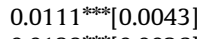 & $1.0399^{* * * *}[0.1148]$ & $0.4639^{* * * *}[0.0972]$ & 0.5822 \\
\hline Latin Am & $01 / 95-12 / 10$ & $0.007^{*}[0.0038]$ & $1.1987^{* * * *}[0.0614]$ & $0.6316^{* * * *}[0.1703]$ & 0.5799 & $01 / 10-12 / 10$ & $0.0138^{* * * *}[0.0026]$ & $1.1798^{* * * *}[0.0662]$ & $0.5498^{* * * *}[0.0606]$ & 0.6801 \\
\hline Africa & $01 / 95-12 / 10$ & $0.0086 *[0.0045]$ & $0.7275^{* * * *}[0.1238]$ & $0.5051^{* * * *}[0.1591]$ & 0.3477 & $01 / 10-12 / 10$ & $0.0126^{* * * k}[0.0053]$ & $0.8433^{* * * *[0.1222]}$ & $0.4692^{* * * *}[0.1664]$ & 0.4305 \\
\hline East. Eu & $01 / 95-12 / 10$ & $0.0073[0.0045]$ & $1.5439^{* * * *}[0.116]$ & $0.3909[0.27]$ & 0.5297 & $01 / 10-12 / 10$ & $0.0107^{* * * k}[0.0041]$ & $1.5293^{* * * *}[0.1352]$ & $0.2441[0.1732]$ & 0.6520 \\
\hline Emerging & $01 / 95-12 / 10$ & $0.0056[0.0039]$ & $1.2126^{* * * *}[0.0575]$ & $0.5438^{* * * * *}[0.1515]$ & 0.6503 & $01 / 10-12 / 10$ & $0.0126^{* * * *}[0.0024]$ & $1.1934^{* * * *}[0.0648]$ & $0.482^{* * *}[0.0625]$ & 0.7407 \\
\hline
\end{tabular}

Standard errors (in square brackets) have been computed using the procedure described in Newey and West (1994).

* Significantly different from zero at the $10 \%$ levels, respectively.

** Significantly different from zero at the $5 \%$ levels, respectively.

***** Significantly different from zero at the $1 \%$ levels, respectively. 
Table 6.2

Conditional CAPM estimation results (Open Interest)

\begin{tabular}{|c|c|c|c|c|c|c|c|c|c|c|}
\hline MSCI TRI & Period & $\alpha$ & $\beta$ & $\varphi$ & $R^{2}$ & Period & $\alpha$ & $\beta$ & $\varphi$ & $R^{2}$ \\
\hline Australia & $01 / 95-12 / 10$ & $0.0039[0.003]$ & $1.1028^{* * * * *}[0.0937]$ & $-0.2971[0.7748]$ & 0.6722 & $01 / 10-12 / 10$ & $0.0095^{* * * * *}[0.0026]$ & $1.1772^{* * * *}[0.1016]$ & $-0.7622[0.7304]$ & 0.7400 \\
\hline Canada & $01 / 95-12 / 10$ & $0.0059^{* * *}[0.0027]$ & $1.1398^{* * * *}[0.064]$ & $0.8085[0.5363]$ & 0.7203 & $01 / 10-12 / 10$ & $0.0091^{* * * *}[0.0025]$ & $1.1313^{* * * *}[0.0753]$ & $1.2753 * * *[0.4155]$ & 0.7442 \\
\hline France & $01 / 95-12 / 10$ & $0.0012[0.0015]$ & $1.174^{* * * *}[0.0481]$ & $-0.1750[0.3008]$ & 0.7903 & $01 / 10-12 / 10$ & $0.0018[0.0015]$ & $1.219^{* * * *[0.0449]}$ & $0.2585[0.3334]$ & 0.8503 \\
\hline Germany & $01 / 95-12 / 10$ & $0.0014[0.0019]$ & $1.2919 * * * 0.0851]$ & $0.3923[0.4745]$ & 0.7552 & $01 / 10-12 / 10$ & $0.0029[0.002]$ & $1.3797^{* * * *}[0.0914]$ & $0.3613[0.6589]$ & 0.8194 \\
\hline Italy & $01 / 95-12 / 10$ & $0.0004[0.0028]$ & $1.1255^{* * * *}[0.0779]$ & $0.3821[0.4691]$ & 0.5748 & $01 / 10-12 / 10$ & $0.0012[0.0027]$ & $1.1652^{* * * *}[0.0853]$ & $0.7969^{* * *}[0.3953]$ & 0.7198 \\
\hline Japan & $01 / 95-12 / 10$ & $-0.0055[0.0035]$ & $0.8361^{* * * *}[0.0728]$ & $-0.6451[0.5893]$ & 0.4622 & $01 / 10-12 / 10$ & $-0.0027[0.003]$ & $0.7566^{* * * *}[0.0712]$ & $-0.2351[0.6282]$ & 0.4980 \\
\hline Neth & $01 / 95-12 / 10$ & $0.0009[0.0018]$ & $1.1875^{* * *+k}[0.065]$ & $-0.1344[0.4526]$ & 0.7758 & $01 / 10-12 / 10$ & $0.0017[0.0019]$ & $1.2559^{* * * *}[0.0591]$ & $0.0671[0.4145]$ & 0.8285 \\
\hline Norway & $01 / 95-12 / 10$ & $0.0037[0.0042]$ & $1.344^{* * * *}[0.1202]$ & $0.0558[1.0434]$ & 0.5956 & $01 / 10-12 / 10$ & $0.0114^{* * * *}[0.003]$ & $1.4552^{* * * *}[0.1184]$ & $0.4401[0.8591]$ & 0.7026 \\
\hline Sing & $01 / 95-12 / 10$ & $0.0012[0.005]$ & $1.1817^{* * * *}[0.1017]$ & $1.1295 *[0.6799]$ & 0.4934 & $01 / 10-12 / 10$ & $0.0063^{*}[0.0035]$ & $1.1037^{* * * *}[0.107]$ & $0.8641[0.7623]$ & 0.5871 \\
\hline Spain & $01 / 95-12 / 10$ & $0.0061^{* * *}[0.0026]$ & $1.2018^{* * * * k}[0.0759]$ & $1.5977^{* *}[0.6289]$ & 0.6600 & $01 / 10-12 / 10$ & $0.0057^{* * *}[0.0029]$ & $1.2407^{* * * * *}[0.0682]$ & $1.0245^{\text {**k }}[0.5114]$ & 0.7080 \\
\hline Switz & $01 / 95-12 / 10$ & $0.0030[0.0021]$ & $0.8365^{* * * *}[0.0492]$ & $-0.5448[0.4248]$ & 0.5777 & $01 / 10-12 / 10$ & $0.0032 * *[0.0015]$ & $0.8468^{* * * *}[0.0516]$ & $-0.7551 *[0.4543]$ & 0.6816 \\
\hline UK & $01 / 95-12 / 10$ & $0.0012[0.0015]$ & $0.8922^{* * * *}[0.0461]$ & $0.4374[0.4043]$ & 0.7958 & $01 / 10-12 / 10$ & $0.0013[0.0013]$ & $0.9552^{* * * *}[0.0393]$ & $0.6584^{* * *}[0.3031]$ & 0.8545 \\
\hline USA & $01 / 95-12 / 10$ & $0.0016[0.0014]$ & $0.9592^{* * * *}[0.0257]$ & $0.0741[0.2217]$ & 0.9017 & $01 / 10-12 / 10$ & $-0.0012[0.0008]$ & $0.9491^{* * * *}[0.0251]$ & $-0.2480 *[0.1474]$ & 0.9389 \\
\hline Arg & $01 / 95-12 / 10$ & $0.0105 *[0.0062]$ & $1.1257^{* * * * *}[0.1681]$ & $4.2002^{* * * *}[1.5614]$ & 0.2513 & $01 / 10-12 / 10$ & $0.0164^{* * *}[0.008]$ & $1.0685^{* * * *}[0.1948]$ & $4.2095^{* * k}[1.9525]$ & 0.2298 \\
\hline Brazil & $01 / 95-12 / 10$ & $0.0106 *[0.0057]$ & $1.6432^{* * * *}[0.1191]$ & $1.6440[1.2068]$ & 0.4664 & $01 / 10-12 / 10$ & $0.0194^{* * * * *}[0.0043]$ & $1.6577^{* * * *}[0.1403]$ & $1.6737[1.2478]$ & 0.5899 \\
\hline Chile & $01 / 95-12 / 10$ & $0.0046[0.005]$ & $0.8676^{* * * *}[0.1009]$ & $0.3430[0.9142]$ & 0.3500 & $01 / 10-12 / 10$ & $0.0134 * *[0.0039]$ & $0.8218^{* * * *}[0.0974]$ & $1.0303[0.7414]$ & 0.4293 \\
\hline China & $01 / 95-12 / 10$ & $-0.0001[0.0065]$ & $1.1574^{* * * * *}[0.1513]$ & $-0.2498[1.4108]$ & 0.2426 & $01 / 10-12 / 10$ & $0.0087^{*}[0.0047]$ & $1.1821^{* * * * *}[0.1584]$ & $-0.1756[1.3136]$ & 0.4486 \\
\hline Colombia & $01 / 95-12 / 10$ & $0.0149 *[0.0079]$ & $0.7596 * * 0.1537]$ & $3.0954 * *[1.2889]$ & 0.1638 & $01 / 10-12 / 10$ & $0.0295^{* * * *}[0.0067]$ & $0.906^{* * * *}[0.1472]$ & $3.7522 * * *[0.9862]$ & 0.2837 \\
\hline Czech Rep. & $01 / 95-12 / 10$ & $0.0089[0.0064]$ & $0.9422^{* * * * *}[0.198]$ & $0.5863[1.3641]$ & 0.2582 & $01 / 10-12 / 10$ & $0.0205^{* * * * *}[0.0055]$ & $1.0728^{* * * * k}[0.179]$ & $1.9876 *[1.1399]$ & 0.4131 \\
\hline Egypt & $01 / 95-12 / 10$ & $0.0134[0.0092]$ & $0.8446 * * * 2166]$ & $-0.0787[1.1839]$ & 0.1606 & $01 / 10-12 / 10$ & $0.0158[0.0108]$ & $0.9671^{* * * *}[0.2368]$ & $0.4454[1.0659]$ & 0.2241 \\
\hline Hungary & $01 / 95-12 / 10$ & $0.011^{*}[0.0058]$ & $1.5304^{* * * *}[0.1837]$ & $2.7621^{* * * *}[1.1794]$ & 0.4355 & $01 / 10-12 / 10$ & $0.0132^{\text {*** }}[0.0061]$ & $1.4998^{* * * *}[0.215]$ & $3.2166^{* * * *}[1.252]$ & 0.5438 \\
\hline India & $01 / 95-12 / 10$ & $0.0046[0.0058]$ & $1.0799^{* * * *}[0.193]$ & $-1.4769[1.1933]$ & 0.2840 & $01 / 10-12 / 10$ & $0.0138^{* * * *}[0.0044]$ & $1.2498^{* * * * k}[0.1867]$ & $0.2906[0.9553]$ & 0.4360 \\
\hline Indonesia & $01 / 95-12 / 10$ & $0.0064[0.0122]$ & $\left.1.4955^{* * * *} 0.2651\right]$ & $-0.2476[1.8156]$ & 0.2364 & $01 / 10-12 / 10$ & $0.0173^{* *}[0.0077]$ & $1.2395^{* * * *}[0.2648]$ & $0.2587[1.3464]$ & 0.3058 \\
\hline Malaysia & $01 / 95-12 / 10$ & $0.0014[0.0087]$ & $0.8367^{* * * *}[0.169]$ & $-0.3231[0.7828]$ & 0.1764 & $01 / 10-12 / 10$ & $0.0082 *[0.0044]$ & $0.5845^{* * * * *}[0.0891]$ & $-0.0845[0.794]$ & 0.2432 \\
\hline Mexico & $01 / 95-12 / 10$ & $0.0076 *[0.004]$ & $1.3115^{* * * *}[0.0829]$ & $1.2902^{* *}[0.5598]$ & 0.5089 & $01 / 10-12 / 10$ & $0.0128^{* * * *}[0.0028]$ & $1.2192^{* * * *}[0.0732]$ & $1.2594 * * * 0.473]$ & 0.6786 \\
\hline Morocco & $01 / 95-12 / 10$ & $0.0081 *[0.0048]$ & $0.2668^{* * *}[0.1176]$ & $-0.4418[0.9248]$ & 0.0451 & $01 / 10-12 / 10$ & $0.0082[0.0055]$ & $0.4262^{* * * * k}[0.113]$ & $-0.2524[0.8958]$ & 0.1146 \\
\hline Phil & $01 / 95-12 / 10$ & $-0.0032[0.0068]$ & $0.9769^{* * * *}[0.1752]$ & $0.2146[1.0219]$ & 0.2315 & $01 / 10-12 / 10$ & $0.0045[0.0059]$ & $0.8031^{* * * *[0.111]}$ & $-0.8615[0.9043]$ & 0.2353 \\
\hline Poland & $01 / 95-12 / 10$ & $0.0049[0.0045]$ & $1.5067^{* * * *}[0.1347]$ & $0.6009[1.1134]$ & 0.4011 & $01 / 10-12 / 10$ & $0.0116^{* * * *}[0.0032]$ & $1.5003^{* * * *}[0.1307]$ & $1.6494 *[0.8699]$ & 0.5286 \\
\hline Russia & $01 / 95-12 / 10$ & $0.0167[0.0112]$ & $1.8281^{* * * *}[0.2736]$ & $-0.3734[2.4725]$ & 0.2546 & $01 / 10-12 / 10$ & $0.0175^{* * * * *}[0.0068]$ & $1.4811^{* * * * *}[0.1694]$ & $1.3856[1.2954]$ & 0.4371 \\
\hline South Afr & $01 / 95-12 / 10$ & $0.0034[0.0047]$ & $1.2455^{* * * *}[0.1155]$ & $-0.6226[1.0566]$ & 0.4748 & $01 / 10-12 / 10$ & $0.0122^{* * * *}[0.0031]$ & $1.2329^{* * * *}[0.1233]$ & $-0.1688[1.1779]$ & 0.5654 \\
\hline South Kor & $01 / 95-12 / 10$ & $0.0018[0.0089]$ & $1.5744^{* * * * *}[0.1388]$ & $-2.8365[1.3349]$ & 0.3336 & $01 / 10-12 / 10$ & $0.0093[0.0068]$ & $1.5243^{* * * * *}[0.1098]$ & $-2.1002[1.3578]$ & 0.5693 \\
\hline Turkey & $01 / 95-12 / 10$ & $0.0125 *[0.0066]$ & $1.937 * * * 0.244]$ & $-1.2539[2.0973]$ & 0.3015 & $01 / 10-12 / 10$ & $0.0145^{* * * *}[0.0055]$ & $1.957^{* * * * *}[0.2862]$ & $1.1970[1.7798]$ & 0.4119 \\
\hline Dev & $01 / 95-12 / 10$ & $0.0006[0.0012]$ & $1.1056^{* * * *}[0.0356]$ & $0.1217[0.2119]$ & 0.9195 & $01 / 10-12 / 10$ & $0.0032^{* * * *}[0.0009]$ & $1.1405^{* * * *}[0.0347]$ & $0.2678[0.1908]$ & 0.9351 \\
\hline Asia & $01 / 95-12 / 10$ & $-0.0004[0.0078]$ & $1.2175^{* * * *}[0.1398]$ & $-0.5067[0.8024]$ & 0.4378 & $01 / 10-12 / 10$ & $0.0096^{* * *}[0.0042]$ & $1.1004^{* * * k \times k}[0.1354]$ & $-0.3253[0.6414]$ & 0.5750 \\
\hline Latin Am & $01 / 95-12 / 10$ & $0.0067 *[0.004]$ & $1.2404^{* * * *}[0.0644]$ & $1.7733^{* * * *}[0.5233]$ & 0.5767 & $01 / 10-12 / 10$ & $0.0139^{* * * *}[0.0026]$ & $1.2118^{* * * *}[0.0609]$ & $1.8841^{* * * *}[0.5279]$ & 0.6796 \\
\hline Africa & $01 / 95-12 / 10$ & $0.0071[0.0047]$ & $0.79^{* * *}[0.1304]$ & $-0.1826[0.7151]$ & 0.3384 & $01 / 10-12 / 10$ & $0.0117^{* * *}[0.0054]$ & $0.8916^{* * * *}[0.1332]$ & $0.4058[0.6571]$ & 0.4243 \\
\hline East. Eu & $01 / 95-12 / 10$ & $0.0066[0.0048]$ & $1.5828^{* * * *}[0.1068]$ & $0.3786[1.1604]$ & 0.5311 & $01 / 10-12 / 10$ & $0.0118^{* * * *}[0.0037]$ & $1.5228^{* * * *}[0.1181]$ & $2.0216^{\text {*** }}[0.8053]$ & 0.6640 \\
\hline Emerging & $01 / 95-12 / 10$ & $0.0051[0.0041]$ & $1.2542^{* * * *}[0.0649]$ & $1.2152^{* *}[0.5012]$ & 0.6450 & $01 / 10-12 / 10$ & $0.0126^{* * * *}[0.0023]$ & $1.2222^{* * * * *}[0.0655]$ & $1.6076^{* * * *}[0.4969]$ & 0.7396 \\
\hline
\end{tabular}

Standard errors (in square brackets) have been computed using the procedure described in Newey and West (1994).

* Significantly different from zero at the $10 \%$ levels, respectively.

** Significantly different from zero at the $5 \%$ levels, respectively.

**** Significantly different from zero at the $1 \%$ levels, respectively. 
In this project, we attempt to discover whether or not the liquidity is internationally priced. We imagine that global liquidity influence stock prices as well as the market price of risk. The open interest and the VIX are used as global liquidity measures. The first measure represents the number of options and/or futures contracts open on the S\&P 500 in a particular day on a specific underlying asset. The VIX is a popular measure of the financial options' implied volatility on the S\&P 500.

To capture the effect of global liquidity on stock returns and on the market price of risk we estimate a conditional two-factor model. Harvey (1995) points out that the conditional estimation allows us to account also for the risk loading time-varying component. We condition the standard CAPM for the non-lagged first differences of the open interest and VIX (see Eqs. (6.1) and (6.2)). Estimation results are reported in Tables 6.1 and 6.2.

$$
\begin{aligned}
& R_{i, t}-R_{f, t}=\alpha_{i}+\beta_{i, m}\left(R_{m, t}-R_{f, t}\right)+\psi_{i}\left[\left(R_{m, t}-R_{f, t}\right) \cdot R_{o p e n}\right]+\varepsilon_{i, t} \\
& R_{i, t}-R_{f, t}=\alpha_{i}+\beta_{i, m}\left(R_{m, t}-R_{f, t}\right)+\phi_{i}\left[\left(R_{m, t}-R_{f, t}\right) \cdot R_{v i x}\right]+e_{i, t}
\end{aligned}
$$

Most of the estimates on the global liquidity measures, captured by the coefficients $\psi_{i}$ and $\phi_{i}$, are statistically significant. These estimates influence positively the stock price and the market price of risk. Let us first focus on the effects of the VIX. For the sample Jan 95-Dec 10, estimation results show that $\psi_{i}$ is statistically significant in 17 stock markets. For the sample Jan 00-Dec 10 this number jumps to 24. We also stress that estimation results are robust in 5 out of 6 portfolios.

The open interest version of the conditional CAPM gives less robust results. The coefficient $\phi_{i}$ is statistically significant only in 8 (Jan 95-Dec 10) and 15 (Jan 00-Dec 10) stock markets. Estimation results confirm that global liquidity affects the market price of risk, in the sense that as liquidity increases in the global market the degree of interdependence between markets increases.

What about model's validity? The interaction component does not influence the intercepts of our country-by-country regressions. In our conditional asset pricing model the null hypothesis of having zero alphas is sporadically rejected, if the sample Jan 95-Dec 10 is analyzed. On the contrary the null is regularly rejected for the sample Jan 00-Dec 10. In other words, model's validity is not preserved. Emerging markets still provide a premium to investors. Our empirical analysis only solves the "beta puzzle".

This result can be a consequence of the linearity assumption. The way in which liquidity affects correlation between stock returns and the return of the market is unknown. The linearity assumption might be too strong. We think that a possible empirical alternative is to estimate the relationship between excess returns and global liquidity factors adopting nonparametric or semiparametric estimation techniques. ${ }^{26}$

\section{Conclusion}

There are several studies on the relationship between liquidity and stock prices. Most of them are based on the US stock market data. We rely mainly on the impact of local and global liquidity on emerging excess returns.

Using a set of "ad hoc" liquid stock country indices (i.e. S\&P IFCI), we confirm the generally accepted idea that investors require to be compensated for investing in exotic stock markets. We name this empirical regularity the "alpha puzzle". Via a two-factor model, we also show that local liquidity factors do not predict emerging average excess returns. We address this issue by means of transaction costs. Using a simple two-country/two-investor partial equilibrium model, we prove that the inclusion of transaction costs leads to higher excess returns. In addition, we show that the spread between developed and emerging average excess returns is an increasing function of the transaction costs parameter.

A second empirical regularity is that the market price of risk in emerging markets has a strong time varying component, namely the "beta puzzle". The conditional two-factor model proves that the global liquidity factors are able, both to predict excess returns and to influence the market price of risk. In specific, global liquidity measures (i.e. VIX and Open Interest) are found to be positive and statistically significant in most emerging stock markets. Given our estimates the "beta puzzle" is explained. In contrast, we still question the validity of the model. We conclude by arguing that the standard asset pricing models are not able to solve simultaneously the two puzzles.

\section{Appendix A. Some empirical facts}

See Figs. A1-A9 and Tables A1 and A3.

\footnotetext{
${ }^{26}$ See, for example, Cai and Kuan (2005).
} 
Kernel density of equity risk premia

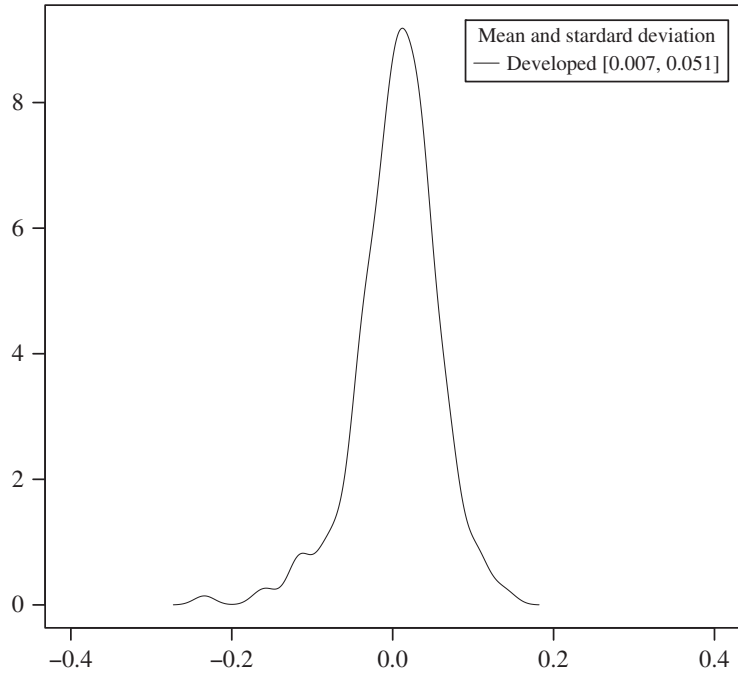

Fig. A.1. Developed portfolio-equity risk premium Kernel Density (sample: Jan 93-Dec 10).

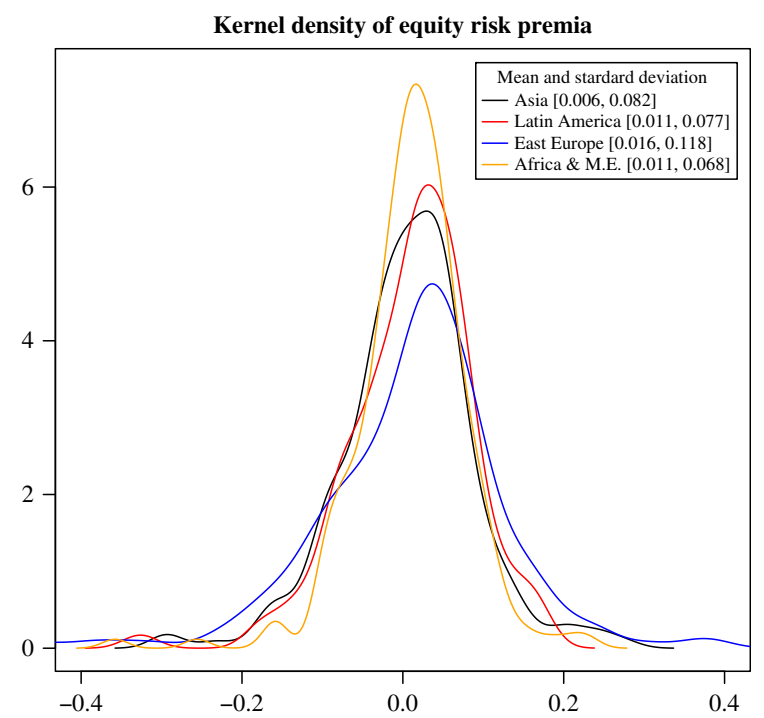

Fig. A.2. Emerging portfolios-equity risk premium Kernel Density (sample: Jan 93-Dec 10). 
Fitted values to predicted values

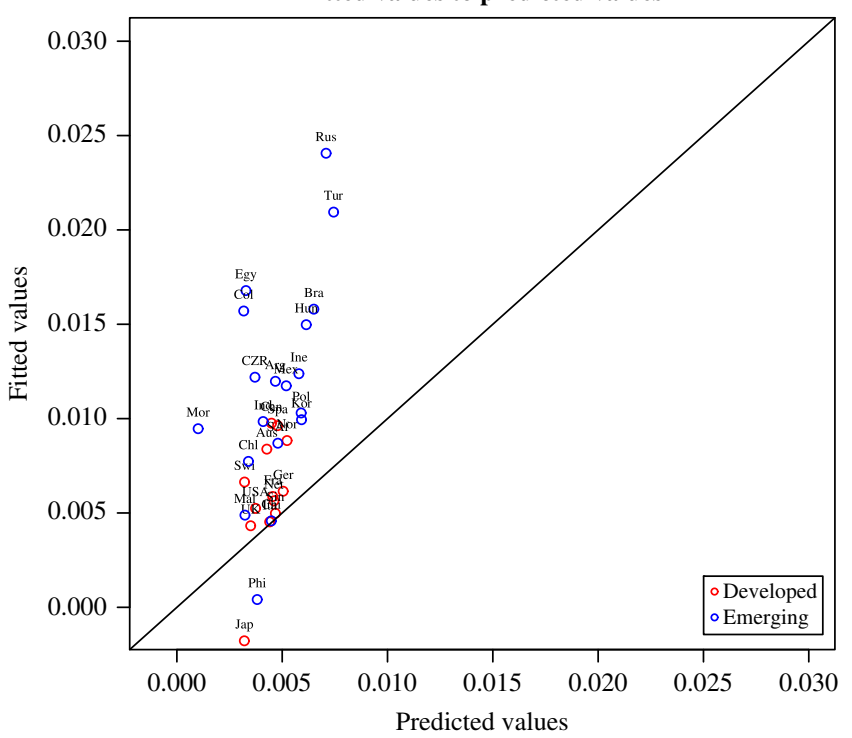

Fig. A.3. Predicted against actual excess returns (sample: Jan 95-Dec 10).

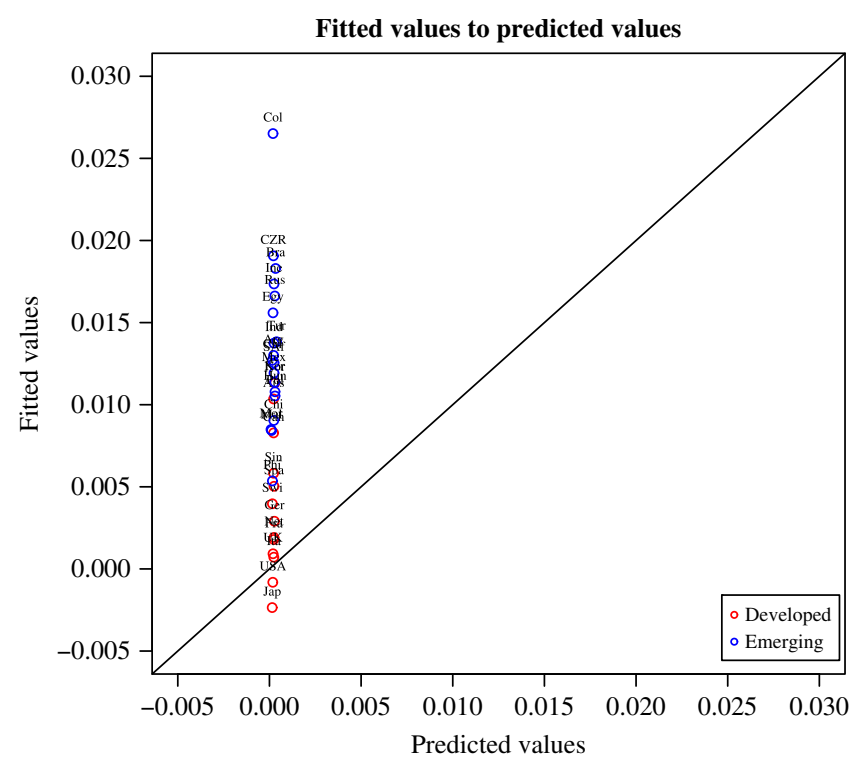

Fig. A.4. Predicted against actual excess returns (sample: Jan 00-Dec 10). 


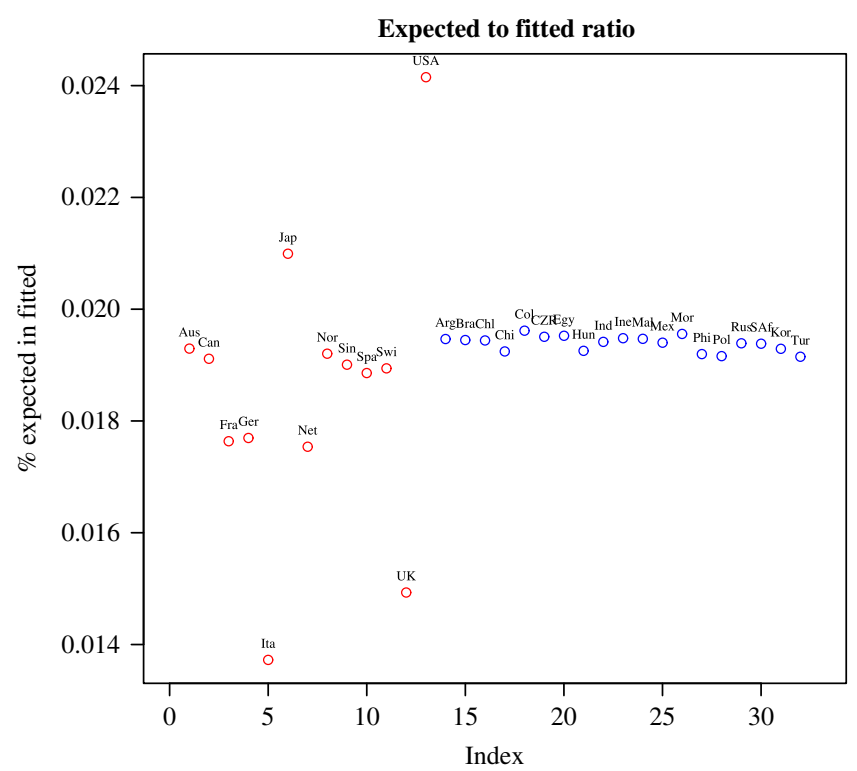

Fig. A.5. Predicted-actual excess returns ratio "MSCI" (sample: Jan 00-Dec 10).

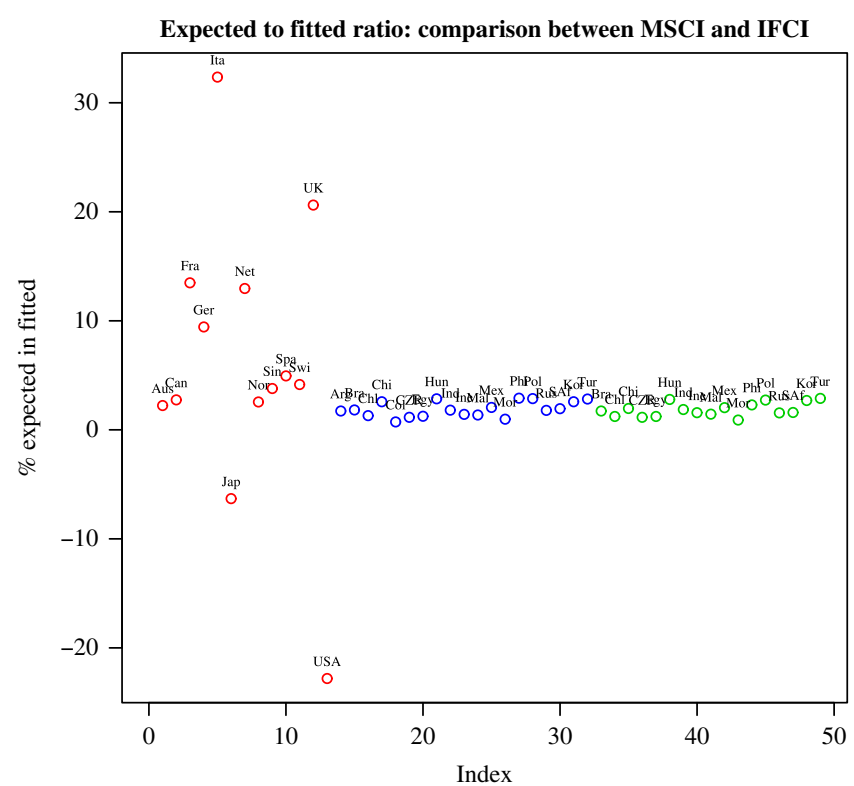

Fig. A.6. Predicted-actual excess returns ratio "MSCI-IFCI" (sample: Jan 00-Dec 10). 


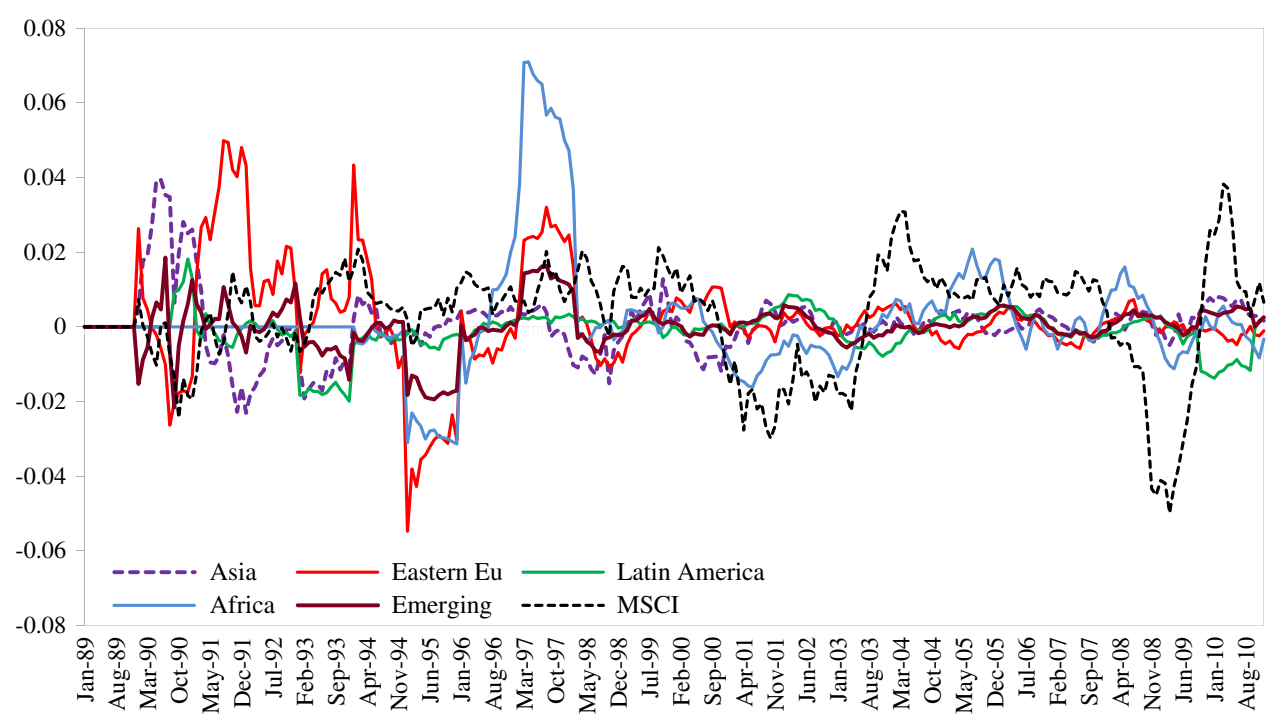

Fig. A.7. MSCI-IFCI Spreads-12 m moving average (sample: Jan 00-Dec 10).

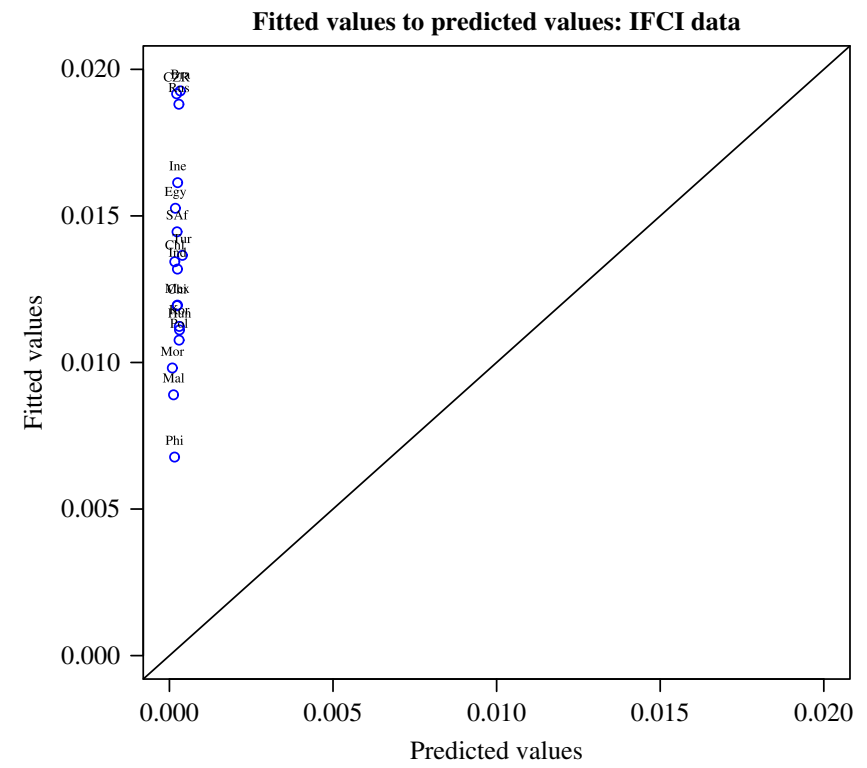

Fig. A.8. Predicted against actual excess returns "IFCI" (sample: Jan 00-Dec 10). 

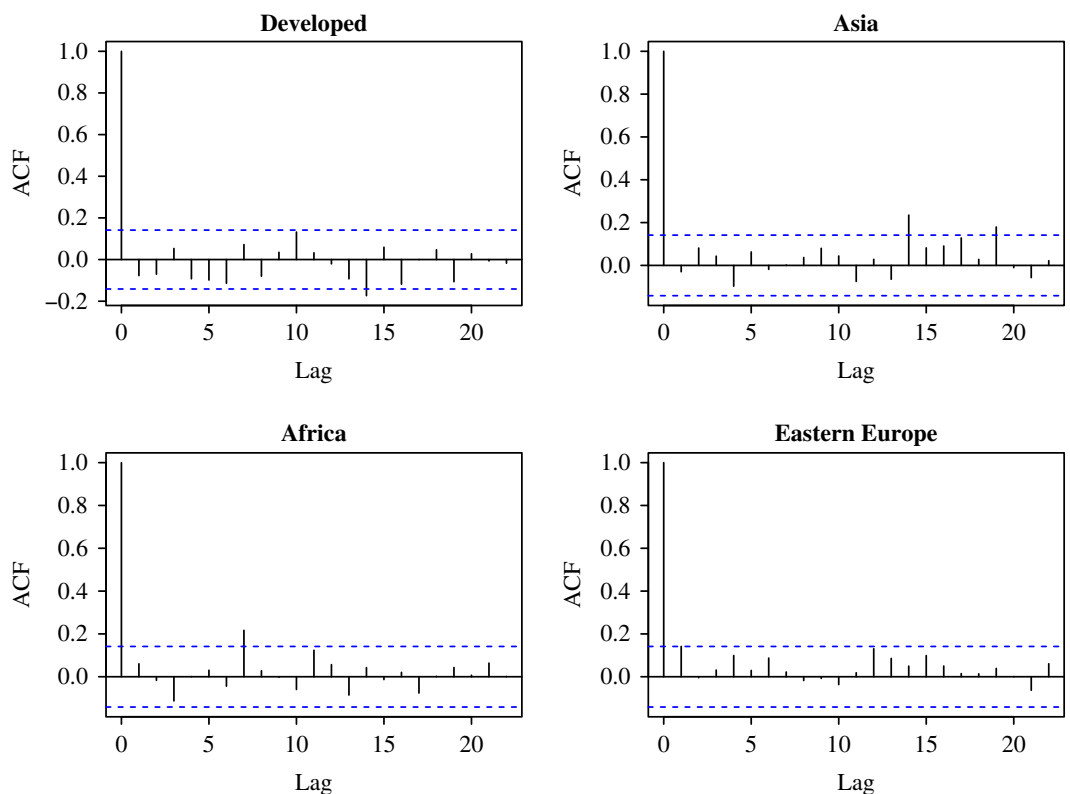

Latin America

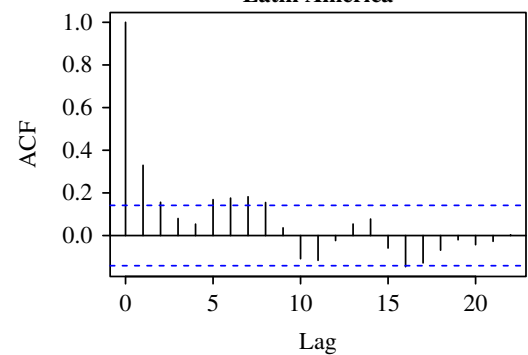

Emerging

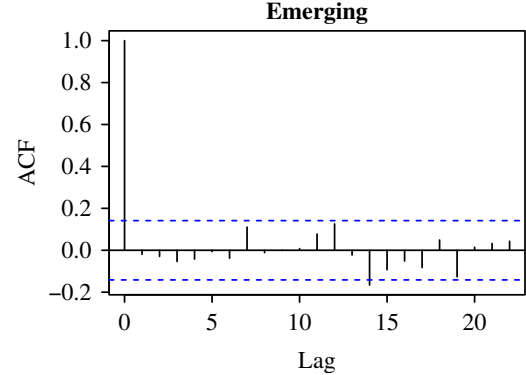

Fig. A.9. Macro-area portfolios: equity risk premia autocorrelation function (sample: Jan 1995-Dec 2010) MSCI TRI.

Table A.1

International stock markets_correlation coefficients (sample: Jan 95-Dec 10).

\begin{tabular}{|c|c|c|c|c|c|c|c|c|c|c|c|c|c|c|c|c|c|c|c|c|}
\hline & US & Arg & $\mathrm{Br}$ & Chile & China & Col & Cz Rep & Egypt & Hun & India & Indon & Mal & Mex & Mor & Philip & Pol & Rus & RSA & Korea & Turkey \\
\hline US & 1.00 & & & & & & & & & & & & & & & & & & & \\
\hline Arg & 0.68 & 1.00 & & & & & & & & & & & & & & & & & & \\
\hline $\mathrm{Br}$ & 0.57 & 0.86 & 1.00 & & & & & & & & & & & & & & & & & \\
\hline Chile & 0.49 & 0.83 & 0.96 & 1.00 & & & & & & & & & & & & & & & & \\
\hline China & 0.13 & 0.71 & 0.74 & 0.74 & 1.00 & & & & & & & & & & & & & & & \\
\hline Col & 0.48 & 0.80 & 0.94 & 0.98 & 0.68 & 1.00 & & & & & & & & & & & & & & \\
\hline Cz Rep & 0.60 & 0.86 & 0.96 & 0.90 & 0.66 & 0.88 & 1.00 & & & & & & & & & & & & & \\
\hline Egypt & 0.63 & 0.89 & 0.96 & 0.90 & 0.68 & 0.89 & 0.98 & 1.00 & & & & & & & & & & & & \\
\hline Hun & 0.74 & 0.86 & 0.85 & 0.79 & 0.53 & 0.78 & 0.92 & 0.93 & 1.00 & & & & & & & & & & & \\
\hline India & 0.62 & 0.87 & 0.97 & 0.95 & 0.73 & 0.93 & 0.95 & 0.96 & 0.89 & 1.00 & & & & & & & & & & \\
\hline Indon & 0.17 & 0.72 & 0.83 & 0.88 & 0.90 & 0.84 & 0.75 & 0.76 & 0.60 & 0.82 & 1.00 & & & & & & & & & \\
\hline Mal & 0.14 & 0.67 & 0.78 & 0.84 & 0.85 & 0.78 & 0.72 & 0.72 & 0.58 & 0.79 & 0.96 & 1.00 & & & & & & & & \\
\hline Mex & 0.69 & 0.89 & 0.95 & 0.92 & 0.63 & 0.91 & 0.97 & 0.97 & 0.94 & 0.97 & 0.74 & 0.71 & 1.00 & & & & & & & \\
\hline Mor & 0.59 & 0.84 & 0.95 & 0.88 & 0.68 & 0.86 & 0.95 & 0.95 & 0.83 & 0.92 & 0.73 & 0.67 & 0.92 & 1.00 & & & & & & \\
\hline Philip & -0.38 & 0.26 & 0.20 & 0.27 & 0.71 & 0.20 & 0.11 & 0.14 & -0.02 & 0.19 & 0.65 & 0.65 & 0.07 & 0.12 & 1.00 & & & & & \\
\hline Pol & 0.67 & 0.93 & 0.89 & 0.83 & 0.68 & 0.80 & 0.94 & 0.95 & 0.96 & 0.92 & 0.72 & 0.71 & 0.95 & 0.87 & 0.19 & 1.00 & & & & \\
\hline Rus & 0.68 & 0.88 & 0.86 & 0.79 & 0.58 & 0.77 & 0.93 & 0.93 & 0.95 & 0.89 & 0.64 & 0.63 & 0.94 & 0.84 & 0.03 & 0.96 & 1.00 & & & \\
\hline RSA & 0.56 & 0.87 & 0.95 & 0.96 & 0.71 & 0.95 & 0.95 & 0.95 & 0.89 & 0.97 & 0.84 & 0.81 & 0.97 & 0.89 & 0.21 & 0.92 & 0.90 & 1.00 & & \\
\hline Korea & 0.59 & 0.85 & 0.90 & 0.89 & 0.66 & 0.87 & 0.94 & 0.93 & 0.91 & 0.95 & 0.78 & 0.78 & 0.95 & 0.84 & 0.19 & 0.93 & 0.92 & 0.96 & 1.00 & \\
\hline Turkey & 0.73 & 0.89 & 0.90 & 0.89 & 0.64 & 0.88 & 0.88 & 0.91 & 0.89 & 0.94 & 0.71 & 0.68 & 0.93 & 0.84 & 0.10 & 0.90 & 0.85 & 0.92 & 0.90 & 1.00 \\
\hline
\end{tabular}


Table A.2

Emerging stock markets-MSCI vs. IFCI stock index.

\begin{tabular}{|c|c|c|c|c|}
\hline Sample & $01 / 95-12 / 10$ & $01 / 00-12 / 10$ & $01 / 95-12 / 10$ & $01 / 00-12 / 10$ \\
\hline Country & MSCI-IFCI (mean spread) (\%) & MSCI-IFCI (mean spread) & IFCI-MSCI (estimated alpha) & IFCI-MSCI (estimated alpha) \\
\hline Argentina & 0.43 & 0.63 & -0.0036 & -0.0040 \\
\hline Brazil & -0.08 & -0.10 & 0.0006 & 0.0009 \\
\hline Chile & -0.07 & -0.07 & 0.0008 & 0.0008 \\
\hline China & -0.41 & -0.29 & 0.0042 & 0.0029 \\
\hline Czech Republic & 0.11 & -0.01 & -0.0013 & -0.0074 \\
\hline Egypt & 0.59 & 0.03 & -0.0051 & -0.0037 \\
\hline Hungary & 0.19 & -0.03 & -0.0018 & -0.0046 \\
\hline India & 0.08 & 0.06 & -0.0007 & 0.0024 \\
\hline Indonesia & 0.08 & 0.12 & -0.0008 & 0.0024 \\
\hline Malaysia & 0.03 & -0.05 & -0.0006 & -0.0083 \\
\hline Mexico & 0.06 & 0.00 & -0.0006 & 0.0034 \\
\hline Morocco & -0.03 & -0.13 & 0.0004 & -0.0020 \\
\hline Philippines & -0.07 & -0.14 & 0.0007 & -0.0018 \\
\hline Poland & -0.02 & -0.02 & 0.0004 & 0.0053 \\
\hline Russia & 0.41 & -0.22 & -0.0025 & 0.0083 \\
\hline South Africa & -0.13 & -0.19 & 0.0014 & -0.0021 \\
\hline South Korea & 0.03 & 0.02 & -0.0005 & -0.0014 \\
\hline Turkey & -0.03 & 0.02 & 0.0004 & 0.0022 \\
\hline Africa & 0.43 & -0.06 & -0.0044 & -0.0041 \\
\hline Asia & 0.05 & 0.06 & -0.0003 & -0.0001 \\
\hline Eastern Europe & 0.16 & 0.02 & -0.0015 & 0.0027 \\
\hline Latin America & -0.01 & -0.04 & 0.0001 & 0.0002 \\
\hline Emerging & 0.14 & 0.11 & -0.0014 & -0.0100 \\
\hline
\end{tabular}


Table A.3

Two-factors model estimation results (turnover-by-volume).

\begin{tabular}{|c|c|c|c|c|c|c|c|c|c|c|}
\hline MSCI/TRI & Period & $\alpha$ & $\beta$ & $\gamma$ & $R^{2}$ & Period & $\alpha$ & $\beta$ & $\gamma$ & $R^{2}$ \\
\hline Argentina & $01 / 95-12 / 10$ & $-0.0037[0.0068]$ & $1.1539 * * * 0.1483]$ & $0.0702^{* *}[0.0313]$ & 0.2880 & $01 / 10-12 / 10$ & $0.0083^{*}[0.0048]$ & $1.1786^{* * * *}[0.1537]$ & $0.0102[0.0117]$ & 0.4416 \\
\hline Brazil & $01 / 95-12 / 10$ & $0.0225^{* * * *}[0.0073]$ & $0.9491 * 0.1711]$ & $0.0334[0.0281]$ & 0.2133 & $01 / 10-12 / 10$ & $0.0242 * * *[0.0069]$ & $0.9671 * * * 0.1677]$ & $0.0495^{*}[0.0267]$ & 0.2561 \\
\hline Chile & $01 / 95-12 / 10$ & $0.0060[0.0067]$ & $0.9551 * * * 0.2006]$ & $0.0181[0.0111]$ & 0.2683 & $01 / 10-12 / 10$ & $0.0166^{* * k}[0.0068]$ & $1.1036^{* * * *}[0.186]$ & $0.0135[0.011]$ & 0.4070 \\
\hline China & $01 / 95-12 / 10$ & $0.0143[0.0092]$ & $0.8431 * * * 0.2255]$ & $-0.0056[0.0061]$ & 0.1533 & $01 / 10-12 / 10$ & $0.0160[0.011]$ & $0.9779 * * * 0.2446]$ & $-0.0048[0.0091]$ & 0.2123 \\
\hline Colombia & $01 / 95-12 / 10$ & $0.0094[0.0062]$ & $1.5778^{* * * *}[0.196]$ & $-0.0010[0.0018]$ & 0.4190 & $01 / 10-12 / 10$ & $0.0099[0.0061]$ & $1.564 * * * * 0.2267]$ & $0.0010[0.0031]$ & 0.5181 \\
\hline Czech Rep & $01 / 95-12 / 10$ & $0.0057[0.0056]$ & $1.0529 * * 0.189]$ & $-0.0001[0.0083]$ & 0.2720 & $01 / 10-12 / 10$ & $0.0144^{* * * *[0.0038]}$ & $1.2558^{* * * *}[0.1878]$ & $-0.0127[0.0157]$ & 0.4309 \\
\hline Egypt & $01 / 95-12 / 10$ & $0.0084[0.0109]$ & $1.52^{* * * *}[0.2605]$ & $0.0089[0.0165]$ & 0.2467 & $01 / 10-12 / 10$ & $0.0165^{* *}[0.0083]$ & $1.2466^{* * * *}[0.2605]$ & $0.0065[0.0202]$ & 0.2955 \\
\hline Hungary & $01 / 95-12 / 10$ & $0.0016[0.0087]$ & $0.8305^{* * * *}[0.165]$ & $0.0030[0.0079]$ & 0.1685 & $01 / 10-12 / 10$ & $0.0076 *[0.0045]$ & $0.57^{* * * *}[0.0956]$ & $0.0159[0.0108]$ & 0.2384 \\
\hline India & $01 / 95-12 / 10$ & $.0102^{* * * *}[0.003]$ & $1.3332 * *[0.0872]$ & $0.0072[0.0103]$ & 0.5536 & $01 / 10-12 / 10$ & $0.0108^{* * *}[0.003]$ & $1.2461 * * *[0.0832]$ & $0.0248[0.0155]$ & 0.6732 \\
\hline Indonesia & $01 / 95-12 / 10$ & $0.0065[0.0053]$ & $0.2533^{* * * *}[0.1214]$ & $0.0108[0.0071]$ & 0.0427 & $01 / 10-12 / 10$ & $0.0074[0.006]$ & $0.4223^{* * * *}[0.1134]$ & $0.0090[0.0082]$ & 0.1069 \\
\hline Malaysia & $01 / 95-12 / 10$ & $-0.0041[0.0068]$ & $0.9779^{* * * *}[0.1821]$ & $0.0087[0.0077]$ & 0.2250 & $01 / 10-12 / 10$ & $0.0040[0.0056]$ & $0.7856^{* * * *}[0.1042]$ & $0.0155[0.0102]$ & 0.2278 \\
\hline Mexico & $01 / 95-12 / 10$ & $0.0040[0.0045]$ & $1.5203^{* * * *}[0.1357]$ & $0.0101[0.0283]$ & 0.3949 & $01 / 10-12 / 10$ & $0.0093^{* * k}[0.0038]$ & $1.5295^{* * * *}[0.1268]$ & $0.0211[0.0282]$ & 0.5194 \\
\hline Morocco & $01 / 95-12 / 10$ & $0.0178[0.0118]$ & $1.8146^{* * * *}[0.2588]$ & $-0.0034[0.0072]$ & 0.2470 & $01 / 10-12 / 10$ & $0.0173^{* * *}[0.0072]$ & $1.5016^{* * *}[0.1763]$ & $-0.0029[0.006]$ & 0.4262 \\
\hline Philippines & $01 / 95-12 / 10$ & $0.0036[0.0048]$ & $1.2365^{* * * *}[0.1085]$ & $0.0018[0.0046]$ & 0.4686 & $01 / 10-12 / 10$ & $0.012^{* * * *}[0.0033]$ & $1.2319 * * *[0.1107]$ & $0.0016[0.0045]$ & 0.5588 \\
\hline Poland & $01 / 95-12 / 10$ & $0.0033[0.0085]$ & $1.5221 * * * 0.1198]$ & $0.0089[0.019]$ & 0.3184 & $01 / 10-12 / 10$ & $0.0082[0.0065]$ & $1.4834^{* * * *}[0.0815]$ & $0.0407 *[0.0192]$ & 0.5749 \\
\hline Russia & $01 / 95-12 / 10$ & $0.0193^{* *}[0.0091]$ & $2.0391 * * * 0.2494]$ & $-0.0255^{*}[0.0147]$ & 0.3661 & $01 / 10-12 / 10$ & $0.0179^{* * *}[0.0077]$ & $2.0063^{* * * *}[0.2914]$ & $-0.0226[0.0173]$ & 0.4130 \\
\hline South Africa & $01 / 95-12 / 10$ & $0.0006[0.0011]$ & $1.1078^{* * *}[0.0381]$ & $0.0000[0.0012]$ & 0.9185 & $01 / 10-12 / 10$ & $0.0028^{* * * *}[0.0009]$ & $1.1432^{* * * k}[0.0377]$ & $0.0041[0.0063]$ & 0.9339 \\
\hline South Korea & $01 / 95-12 / 10$ & $-0.0004[0.0076]$ & $1.2123 * * * 0.1327]$ & $0.0065[0.0104]$ & 0.4319 & $01 / 10-12 / 10$ & $0.0093^{* * *}[0.0042]$ & $1.1038^{* * * *}[0.1261]$ & $0.0134[0.0112]$ & 0.5715 \\
\hline Turkey & $01 / 95-12 / 10$ & $0.0038[0.0044]$ & $1.2649^{* * * *}[0.0711]$ & $0.0148^{* *}[0.0064]$ & 0.5700 & $01 / 10-12 / 10$ & $0.0114^{* * * *}[0.0028]$ & $1.2402^{* * *}[0.0727]$ & $0.0109 *[0.0059]$ & 0.6660 \\
\hline US & $01 / 95-12 / 10$ & $0.0017[0.0014]$ & $0.961 * * 0.0259]$ & $-0.0075[0.0063]$ & 0.9015 & $01 / 10-12 / 10$ & $-0.0009[0.0008]$ & $0.9448 * * * 0.0269]$ & $-0.0037[0.0056]$ & 0.9376 \\
\hline Asia & $01 / 95-12 / 10$ & $-0.0005[0.0076]$ & $1.2039^{* * * *}[0.1327]$ & $0.0084[0.0108]$ & 0.4321 & $01 / 10-12 / 10$ & $0.01^{* * * *}[0.0039]$ & $1.0957^{* * * *}[0.1328]$ & $-0.0019[0.0121]$ & 0.5680 \\
\hline East. Eu. & $01 / 95-12 / 10$ & $0.0054[0.0046]$ & $1.5832^{* * * *[0.109]}$ & $0.0070[0.007]$ & 0.5270 & $01 / 10-12 / 10$ & $0.0085^{\text {**k }}[0.0038]$ & $1.545^{* * * *}[0.125]$ & $0.0131[0.0086]$ & 0.6549 \\
\hline Latina America & $01 / 95-12 / 10$ & $0.0062[0.004]$ & $1.2729 * * *[0.0743]$ & $-0.0146[0.0112]$ & 0.5685 & $01 / 10-12 / 10$ & $0.0129^{* * * *}[0.0025]$ & $1.2485^{* * * *}[0.0742]$ & $-0.0069[0.0097]$ & 0.6634 \\
\hline Emerging & $01 / 95-12 / 10$ & $0.0037[0.0041]$ & $1.2761 * * * 0.0681]$ & $0.0194^{* * * * *}[0.0052]$ & 0.6531 & $01 / 10-12 / 10$ & $0.0098^{* * *}[0.0027]$ & $1.2492^{* * * k}[0.0739]$ & $0.0175^{* * * * *}[0.0046]$ & 0.7316 \\
\hline
\end{tabular}

Standard errors (in square brackets) have been computed using the procedure described in Newey and West (1994).

* Significantly different from zero at the $10 \%$ levels, respectively.

*** Significantly different from zero at the $5 \%$ levels, respectively.

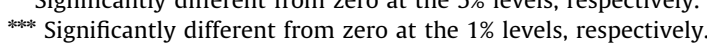




\section{Appendix B. The model}

Proof of Proposition 1. Miller (1981) suggests that, if

$$
\left(\boldsymbol{V}+r^{f} \boldsymbol{B}\right)
$$

is invertible and $\boldsymbol{B}$ has rank 1, then we can always express the inverse of the sum of these two matrices as

$$
\left(\boldsymbol{V}+r^{f} \boldsymbol{B}\right)=\boldsymbol{V}^{-1}-\frac{r^{f}}{1+g} \boldsymbol{V}^{-1} \boldsymbol{B} \boldsymbol{V}^{-1}
$$

where

$$
g=\operatorname{tr}\left(\boldsymbol{B} \boldsymbol{V}^{-1}\right)>0
$$

Since $V$ is invertible and $\beta$ is positive the determinant of

$$
\left(\boldsymbol{V}+r^{f} \boldsymbol{B}\right)
$$

is always different than zero, hence the matrix is actually invertible.

We define

$$
\frac{r^{f}}{1+g}=\frac{r^{f}}{1+\sigma_{d}^{2}+\sigma_{e}^{2}+r^{f} \beta}=k>0
$$

Hence we can rewrite (5.11) as follows:

$$
\left[\left[\boldsymbol{V}^{-1}-k \boldsymbol{V}^{-1} \boldsymbol{B} \boldsymbol{V}^{-1}+\boldsymbol{V}^{-1}\right]^{-1}-\frac{1}{2} \boldsymbol{V}\right] \mathbf{1}=\left[\left[2 \boldsymbol{V}^{-1}-k \boldsymbol{V}^{-1} \boldsymbol{B} \boldsymbol{V}^{-1}\right]^{-1}-\frac{1}{2} \boldsymbol{V}\right] \mathbf{1}=\left[\left[2 \boldsymbol{V}^{-1}-k \boldsymbol{Q}\right]^{-1}-\frac{1}{2} \boldsymbol{V}\right] \mathbf{1}
$$

where

$$
\boldsymbol{Q}=\boldsymbol{V}^{-1} \boldsymbol{B} \boldsymbol{V}^{-1}=\left[\begin{array}{cc}
\frac{r^{f} \beta \sigma_{d e}^{2}}{D^{2}} & -\frac{r^{f} \beta \sigma_{d e} \sigma_{d}^{2}}{D^{2}} \\
-\frac{r^{f} \beta \sigma_{d e} \sigma_{d}^{2}}{D^{2}} & \frac{r^{f} \beta\left(\sigma_{d}^{2}\right)^{2}}{D^{2}}
\end{array}\right]
$$

and $D=\operatorname{det}(\boldsymbol{V})$. We can easily check that the determinant of $\boldsymbol{Q}$ is equal to zero, indeed the matrix has rank 1 .

Applying again Miller's (1981) results for

$$
\left[2 \boldsymbol{V}^{-1}-k \boldsymbol{Q}\right]^{-1}
$$

we have the following:

$$
\left[2 \boldsymbol{V}^{-1}-k \boldsymbol{Q}\right]^{-1}=\frac{1}{2} \boldsymbol{V}+\frac{4 k}{1+\operatorname{tr}(\mathbf{Q})} \boldsymbol{V} \boldsymbol{V}^{-1} \boldsymbol{B} \boldsymbol{V}^{-1} \boldsymbol{V}=\frac{1}{2} \boldsymbol{V}+\frac{4 k}{1+\operatorname{tr}(\mathbf{Q})} \boldsymbol{B}
$$

Rewriting Eq. (A.1) we can conclude that

$$
\hat{\boldsymbol{e}}^{*}-\boldsymbol{e}^{*}=\frac{4 k}{1+\operatorname{tr}(\boldsymbol{Q})} \boldsymbol{B} 1=\frac{4 k}{1+\operatorname{tr}(\mathbf{Q})}\left[\begin{array}{l}
0 \\
\beta
\end{array}\right]>0,
$$

where

$$
\hat{\boldsymbol{e}}^{*}=\left(\hat{e}-\mathbf{1} r^{f}\right)
$$

and

$$
\boldsymbol{e}^{*}=\left(\boldsymbol{e}-\mathbf{1} r^{f}\right)
$$

Being $k, \beta, \operatorname{tr}(\boldsymbol{Q})>0$ positive scalars, the inequality holds. The proof is complete.

\section{References}

Acharya, V.V., Pedersen, L.H., 2005. Asset pricing with liquidity risk. Journal of Financial Economics 77, 375-410.

Ahearne, A.G., Griever, W.L., Warnock, F.E., 2004. Information costs and home bias: an analysis of U.S. holdings of foreign equities. Journal of International Economics 62 (2), 313-336.

Aiyagari, R.S., 1993. Explaining financial market facts: the importance of incomplete markets and transaction costs. Federal Reserve Bank of Minneapolis Quarterly Review 17 (1), 17-31. 
Akbas, F., Armstrong, W.J., Petkova, R., 2011. The Volatility of Liquidity and Expected Stock Returns. Working Paper Series. Department of Finance, Texas A\&M University.

Amihud, Y., 2002. Illiquidity and stock returns: cross-section and time-series effects. Journal of Financial Markets 5, 31-56.

Amihud, Y., Mendelson, H., 1986. Asset pricing and the bid-ask spread. Journal of Financial Economics 17, $223-249$.

Amihud, Y., Mendelson, H., 1990. The liquidity and the 1987 stock market crash. The Journal of Portfolio Management 16 (3), 65-69.

Amihud, Y., Mendelson, H., Pedersen, L.H., 2005. Liquidity and asset prices. Foundations and Trends in Finance 1 (4), $269-364$.

Baker, M., Stein, J.C., 2002. Market Liquidity as a Sentiment Indicator. NBER Working Papers 8816.

Barry, C.B., Peavy III, J.W., Rodriguez, M., 1997. A convenient way to invest in emerging markets. Emerging Markets Quarterly 1 (1), 41-48.

Bekaert, G., Erb, C., Harvey, C., Viskanta, T., 1998. The behavior of emerging market returns. In: Levich, Richard (Ed.), Emerging Market Capital Flows, New York, 1998, pp. 107-173.

Bekaert, G., Harvey, C.R., 1997. Emerging equity market volatility. Journal of Financial Economics 43, 29-77.

Bekaert, G., Harvey, C.R., 1995. Time-varying world market integration. Journal of Finance 50, 403-444.

Bekaert, G., Harvey, C.R., 2003a. Emerging markets finance. Journal of Empirical Finance 10, 3-55.

Bekaert, G., Harvey, C.R., Lundblad, C., 2007. Liquidity and expected returns: lessons from emerging markets. Review of Financial Studies 20 (6), 1783-1831.

Black, F., Jensen, M.C., Scholes, M., 1972. The capital asset pricing model: some empirical tests.. In: Jensen, Michael (Ed.), Studies in the Theory of Capital Markets, Praeger, New York, pp. 79-121.

Brennan, M.J., Subrahmanyam, A., 1996. Market microstructure and asset pricing: on the compensation for illiquidity in stock returns. Journal of Financial Economics 41, 441-464.

Brennan, M.J., Cordia, T., Subrahmanyam, A., 1998. Alternative factor specifications, security characteristics, and the cross-section of expected stock returns. Journal of Financial Economics 49 (3), 345-373.

Brooks, R., Del Negro, M., 2002. International Diversification Strategies. Federal Reserve Bank of Atlanta Working Papers No. 23/02.

Cai, Z., Kuan, C.M., 2005. In: Non Parametric Modelling for Conditional Asset Pricing ModelMimeo.

Chalmers, J.M., Kadlec, G.B., 1998. An empirical examination of the amortized spread. Journal of Financial Economics 48, $159-188$.

Chan, J.P., 2002. Persistent Liquidity and Expected Return. University of California Working Paper.

Chordia, T., Roll, R., Subrahmanyam, A., 2000. Commonality in liquidity. Journal of Financial Economics 56, 3-28.

Chordia, T., Subrahmanyam, A., Anshuman, V.R., 2001b. Trading activity and expected stock returns. Journal of Financial Economics 59, 3-32.

Claessens, S., Dasgupta, S., Glen, J., 1995. Return behavior in emerging stock markets. World Bank Economic Review 9 (1), 131-151.

Datar, V.T., Naik, N.Y., Radcliffe, R., 1998. Liquidity and stock returns: an alternative test. Journal of Financial Markets 1, $203-219$.

Domowitz, I., Glen, J., Madhavan, A., 2001. Liquidity, volatility and equity trading costs across countries and over time. International Finance 4 (2), 221-255.

Domowitz, I., Jack Glen, J., Madhavan, A., 1997a. Market segmentation and stock prices: evidence from an emerging market. The Journal of Finance 52 (3), 1059-1085.

Domowitz, I., Jack Glen, J., Madhavan, A., 1997b. Liquidity, volatility and equity trading costs across countries and over time. International Finance 4 (2), 221-255.

Donadelli, M., Prosperi, L., 2011. Understanding the Equity Risk Premium: Empirical Evidence from Emerging Markets. CASMEF Working Paper 2012/01. Easley, D., Hvidkjær, S., O'Hara, M., 2002. Is information risk a determinant of asset returns? Journal of Finance 57, 2185-2221.

Eleswarapu, V.R., 1997. Cost of transacting and expected returns in the Nasdaq markets. Journal of Finance 52 (5), $2113-2127$.

Eleswarapu, V.R., Reinganum, M.R., 1993. The seasonal behavior of the liquidity premium in asset pricing. Journal of Financial Economics 34, 373-386.

Eun, C.S., Janakiramanan, S., 1986. A model of international asset pricing with a constraint on the foreign equity ownership. The Journal of Finance 41 (4), $897-914$.

Fujimoto, A., 2003. Liquidity and Expected Market Returns: An Alternative test, Yale University Working Paper.

Gibbons, M.R., Ross, S.A., Shanken, J., 1989. A test of the efficiency of a given portfolio. Econometrica 57 (5), 1121-1152.

Harvey, C., 1995. The cross-section of volatility and autocorrelation in emerging equity markets. Finanzmarkt und Portfolio Management 9, 134-147.

Harvey, C.R., 2004. Country Risk Components, The Cost of Capital, and Returns in emerging markets. NBER Working Paper.

Harvey, C.R., 1994. Conditional Asset Allocation in Emerging Markets. NBER Working Paper No. 4623.

Henry, P.B., 2000. Stock market liberalization, economic reform, and emerging equity market prices. Journal of Finance 55, 529-564.

Hietala, P.T., 1989. Asset pricing in partially segmented markets: evidence from the Finnish market. Journal of Finance 44, 697-718.

Jagannathan, R., McGrattan, E.R., Scherbina, A., 2000. The declining U.S. equity premium. Federal Reserve Bank of Minneapolis Quarterly Review 24 (4),

3-19.

Jones, C., 2002. A Century of Stock Market Liquidity and Trading Costs. Columbia University Working Paper.

Jun, S., Marathe, A., Shawky, H.A., 2003. Liquidity and stock returns in emerging equity markets. Emerging Markets Review 4 (1), 1-24.

Kyle, A., 1985. Continuous auctions and insider trading. Econometrica 53, 1315-1335.

Lesmond, D., Ogden, J., Trzcinka, C., 1999. A new estimate of transaction costs. Review of Financial Studies 12, $1113-1141$.

Liu, W., 2006. A liquidity-augmented capital asset pricing model. Journal of Financial Economics 82, 631-671.

Miller, K.S., 1981. On the inverse of the sum of matrices. Mathematics Magazine 54 (2), 67-72.

Newey, W.K., West, K.D., 1994. Automatic lag selection in covariance matrix estimation. Review of Economic Studies 61 (4), 631-653.

Pastor, L., Stambaugh, R., 2003. Liquidity risk and expected stock returns. Journal of Political Economy 111, $642-685$.

Roll, R., 1984. A simple implicit measure of the effective bid-ask spread in an efficient market. Journal of Finance 39, 1127-1139.

Salomons, R., Grootveld, H., 2003. The equity risk premium: emerging vs. developed markets. Emerging Markets Review 4 (2), $121-144$.

Scott, R.C., Horvath, P.A., 1980. On the direction of preference for moments of higher order than the variance. Journal of Finance 35, 915-919.

Sharpe, W., 1964. Capital asset prices: a theory of capital market equilibrium under conditions of risk. Journal of Finance $19,425-442$.

Stulz, R.M., 1981. On the effects of barriers to international investment. Journal of Finance 36 (4), $923-934$.

Zhang, H., 2010. Measuring Liquidity in Emerging Markets. National University of Singapore, Mimeo, NUS Business School. 